\title{
On the segregation of chemical species in a clear boundary layer over heterogeneous land surfaces
}

\author{
H. G. Ouwersloot ${ }^{1,3}$, J. Vilà-Guerau de Arellano ${ }^{1}$, C. C. van Heerwaarden ${ }^{1}$, L. N. Ganzeveld ${ }^{2}$, M. C. Krol ${ }^{1}$, and \\ J. Lelieveld ${ }^{3}$ \\ ${ }^{1}$ Meteorology and Air Quality, Wageningen University, Wageningen, The Netherlands \\ ${ }^{2}$ Earth System Sciences - Climate Change, Wageningen University, Wageningen, The Netherlands \\ ${ }^{3}$ Max Planck Institute for Chemistry, Mainz, Germany
}

Received: 23 June 2011 - Published in Atmos. Chem. Phys. Discuss.: 1 July 2011

Revised: 17 October 2011 - Accepted: 18 October 2011 - Published: 28 October 2011

\begin{abstract}
Using a Large-Eddy Simulation model, we have systematically studied the inability of boundary layer turbulence to efficiently mix reactive species. This creates regions where the species are accumulated in a correlated or anti-correlated way, thereby modifying the mean reactivity. We quantify this modification by the intensity of segregation, $I_{\mathrm{S}}$, and analyse the driving mechanisms: heterogeneity of the surface moisture and heat fluxes, various background wind patterns and non-uniform isoprene emissions. The heterogeneous surface conditions are characterized by cool and wet forested patches with high isoprene emissions, alternated with warm and dry patches that represents pasture with relatively low isoprene emissions. For typical conditions in the Amazon rain forest, applying homogeneous surface forcings and in the absence of free tropospheric $\mathrm{NO}_{\mathrm{x}}$, the isoprene$\mathrm{OH}$ reaction rate is altered by less than $10 \%$. This is substantially smaller than the previously assumed $I_{\mathrm{S}}$ of $50 \%$ in recent large-scale model analyses of tropical rain forest chemistry. Spatial heterogeneous surface emissions enhance the segregation of species, leading to alterations of the chemical reaction rates up to $20 \%$. The intensities of segregation are enhanced when the background wind direction is parallel to the borders between the patches and reduced in the case of a perpendicular wind direction. The effects of segregation on trace gas concentrations vary per species. For the highly reactive $\mathrm{OH}$, the differences in concentration averaged over the boundary layer are less than $2 \%$ compared to homogeneous surface conditions, while the isoprene concentration is increased by as much as $12 \%$ due to the reduced chemical reaction rates. These processes take place at the sub-grid scale of chemistry transport models and therefore need to be parameterized.
\end{abstract}

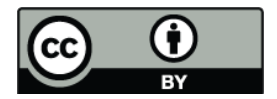

Correspondence to: H. G. Ouwersloot (huug.ouwersloot@wur.nl)

\section{Introduction}

The Amazonian region is an area of great interest for the global climate, since the rain forest exchanges large quantities of carbon containing species with the atmosphere. This area is steadily changing from a natural environment to a human-controlled environment associated with deforestation (Andreae and et al., 2002; Soares-Filho et al., 2006), causing changes in surface conditions and, consequently, boundary layer characteristics (Fisch et al., 2004) and trace gas exchanges (Ganzeveld et al., 2010). To evaluate these changes and their influence on atmospheric chemistry and global climate, the understanding of the boundary layer dynamics and atmospheric chemistry over the Amazonian system needs to be improved.

We present a numerical model study that focuses on the effects of surface heterogeneity on atmospheric dynamics and chemistry. Both are affected by mesoscale circulations induced by spatial differences in sensible and latent heat fluxes and additionally, chemistry is affected by non-uniform reactant emissions at the surface. Therefore, because of spatial variations of surface properties, chemical reactants can either be separated more strongly or be more efficiently mixed by circulations, as we will investigate. Other dynamical aspects relevant for chemistry, like the boundary layer height development or turbulent mixing, are dependent on the surface heterogeneity as well. Although many studies have been performed on the effects on the dynamics (Avissar and Liu, 1996; Patton et al., 2005; van Heerwaarden and VilàGuerau de Arellano, 2008), the effects on atmospheric chemistry have been investigated much less intensively (Krol et al., 2000; Auger and Legras, 2007). To our knowledge a systematic study on the impact of surface heterogeneities on simultaneously boundary layer dynamics and chemistry has not yet been performed. 
Tropical rain forest chemistry is driven by the exchange of biogenic compounds, dynamic processes like turbulent mixing, and the diurnal variability of the atmospheric boundary layer (ABL). The influence of ABL dynamics on chemistry is often crudely described in large-scale atmospheric models and in models that are used to analyse experimental observations (Ganzeveld et al., 2008; Vilà-Guerau de Arellano et al., 2009). A list of the most important influences is presented in Table 1.

Recently, one of these processes, the segregation of species due to inefficient turbulent mixing, has been recognized as a possible relevant process to take into account in the observational analyses and models (Butler et al., 2008; Pugh et al., 2010, 2011). This segregation of species was previously studied for idealized cases (Schumann, 1989; Sykes et al., 1992; Vilà-Guerau de Arellano et al., 1993). The inability of turbulence to uniformly mix the emitted and entrained species creates sub-regions where the species are non-uniformly distributed in a correlated or anti-correlated way, thereby modifying the mean chemical reaction rate in the boundary layer. The early studies focused on the boundary layer dynamics and did not consider complex chemistry. Krol et al. (2000) conducted a study for more complex chemistry using a Large-Eddy Simulation (LES) model and investigated the effect of heterogeneous surface emissions of biogenic reactive compounds on the intensity of segregation. They found that non-uniform emissions significantly enhance the segregation of reactants.

The acquired knowledge of these studies has only rarely been applied to atmospheric chemistry models and measurement analyses. Auger and Legras (2007) investigated the segregation effects for urban air chemistry for both homogeneous and heterogeneous reactant emissions while keeping the surface conditions that drive the dynamics uniform over the domain. The intensity of segregation is also considered as a potential contributor to large discrepancies between observations and model results of reactive trace gas concentrations over the tropical forest, particularly for the biogenic volatile organic compound isoprene and the hydroxyl radical $(\mathrm{OH})$ (Butler et al., 2008).

In the analysis of observations ad hoc values of the intensity of segregation have been assumed that correspond to a substantial decrease in the isoprene- $\mathrm{OH}$ reaction rate, while not taking the governing physical and chemical processes into account (e.g. Butler et al., 2008; Pugh et al., 2010). Observations on the intensity of segregation between $\mathrm{OH}$ and isoprene, by relatively fast simultaneous measurements of both compounds over a German deciduous forest, were made by Dlugi et al. (2010). However, they only measured at one location and one height, $7 \mathrm{~m}$ above the forest canopy. Therefore their result, a decrease in the chemical reaction rate of $15 \%$, is representative for the surface layer of the atmospheric boundary layer. Butler et al. (2008) made use of averaged aircraft measurements taken with a low frequency ( $5 \mathrm{~s}$ ) compared to the flight speed. Their result, which corresponds to a decrease in the chemical reaction rate of $13 \%$ compared to perfect mixing conditions, is therefore a first indication for the segregation within the Amazonian atmospheric boundary layer. However, their measurements do not capture the fine dynamical structures associated to the small scales of convective turbulence. It can not be inferred whether the total intensity of segregation is weaker or stronger, since these fine structures can lead to either positive or negative contributions.

The aim of the present work is to systematically study the intensity of segregation for the isoprene- $\mathrm{OH}$ reaction under conditions representative for the Amazon rain forest using a LES model. This reaction is of interest since $\mathrm{OH}$ chemistry largely controls the oxidizing capacity of the atmosphere, both worldwide and above the Amazon rain forest (Zimmerman et al., 1988; Karl et al., 2007; Lelieveld et al., 2008). The intensity of segregation can be calculated explicitly in the LES, in contrast to mesoscale models and global climate models where segregation is a sub-grid scale process. In consequence, the LES experiments enable us to determine the governing processes, which will be combined with investigating the impact of surface heterogeneities on the segregation effect and the boundary layer growth under different conditions.

The next section introduces the model and the numerical experiments. Subsequently, the method of calculating the intensity of segregation is explained. The first results presented are the dynamical and chemical characteristics of the cases with the standard homogeneous and heterogeneous surface conditions. This is followed by a sensitivity analysis for several governing variables affecting the impact of the surface heterogeneities.

\section{Methodology}

\subsection{Model}

This study makes use of a modified version 3.2 of the Dutch Atmospheric Large-Eddy Simulation (DALES) model (Heus et al., 2010). This LES model originates from Nieuwstadt and Brost (1986) and has been further developed and improved since (e.g. Cuijpers and Duynkerke, 1993; Dosio, 2005). DALES explicitly resolves processes on a relatively large scale using the filtered Navier-Stokes equations in combination with the Boussinesq approximation (Heus et al., 2010). In general, the filter size is set equal to the grid size of the simulations. Subfilter-scale processes are parameterized using one-and-a-half-order closure. The boundary conditions in the horizontal directions are periodic. DALES 3.2 is extended with a chemistry module, thus allowing for simultaneous simulation of both boundary layer dynamics and chemistry (Vilà-Guerau de Arellano et al., 2005).

Our model is modified with respect to the standard DALES 3.2 to the extent that the domain can be divided in patches for 
Table 1. Influence of ABL dynamics, radiation and surface conditions on atmospheric chemistry.

\begin{tabular}{|c|c|}
\hline Influence & Effect on chemistry \\
\hline \multirow[t]{2}{*}{ Boundary layer growth } & Lowering concentrations by dilution \\
\hline & Entrainment of air from the free troposphere \\
\hline \multirow[t]{4}{*}{ Clouds } & Photolysis rate modification by radiation scattering \\
\hline & Impact on photosynthetically active radiation \\
\hline & $\begin{array}{l}\text { Enhancement of the vertical transport of chemical com- } \\
\text { pounds }\end{array}$ \\
\hline & Venting chemical compounds to the free troposphere \\
\hline Turbulence & $\begin{array}{l}\text { Driver of the mixing of air: organized in coherent structures } \\
\text { leading to inefficient turbulent mixing that can create a seg- } \\
\text { regation of species which alters the mean reactivity }\end{array}$ \\
\hline Temperature & Modification of reaction rate coefficients \\
\hline Moisture & $\begin{array}{l}\text { Influence on reactivity as a catalyst or reactant (e.g. the for- } \\
\text { mation of } \mathrm{OH} \text { ) }\end{array}$ \\
\hline Atmosphere-vegetation-soil interaction & $\begin{array}{l}\text { Emission and deposition fluxes of chemical compounds } \\
\text { (isoprene, ozone) depending on the radiation, canopy char- } \\
\text { acteristics and both atmospheric and soil conditions con- } \\
\text { cerning temperature and moisture }\end{array}$ \\
\hline Surface heterogeneity & $\begin{array}{l}\text { Modification of the dynamics by induction of mesoscale cir- } \\
\text { culations and the chemistry by non-uniform emission or de- } \\
\text { position fluxes of reactants. In consequence, potential en- } \\
\text { hancement of spatial reactant segregation }\end{array}$ \\
\hline
\end{tabular}

which the boundary conditions at the surface can be generically set instead of assuming uniform surface conditions. For these patches, the number of grid points in each horizontal dimension is required to be equal to the total number of grid points in that dimension divided by a power of 2 . The kinematic surface fluxes for heat and moisture are prescribed for each patch.

\subsection{Model setup}

For all cases in this study the resolution of the LES domain is set to $50 \mathrm{~m} \times 50 \mathrm{~m} \times 20 \mathrm{~m}$ in the $\mathrm{x}, \mathrm{y}$ and $\mathrm{z}$ directions respectively. The standard grid size is $256 \times 256 \times 128$, resulting in a simulated domain of $12800 \mathrm{~m} \times 12800 \mathrm{~m} \times 2560 \mathrm{~m}$. The simulations are run for $4 \mathrm{~h}$ with a maximum time step of $1 \mathrm{~s}$. This time step is small enough to prevent instabilities in the chemical solver. With these settings the relevant temporal and spatial scales for both atmospheric dynamics and chemistry are resolved. Output is generated every minute and the first hour is considered as spin-up of the model. The chemical and dynamical input data of the control cases are based on measurements in the Amazonian rain forest during the TROFFEE campaign that was conducted 14-29 September 2004 (Karl et al., 2007; Vilà-Guerau de Arellano et al., 2011).
In order to investigate the effects of surface heterogeneity without the effects of the diurnal variability, the cases are based on noon conditions characterized by a well-developed boundary layer. The initial boundary layer height is set to $1000 \mathrm{~m}$. We assume no large scale subsidence and, in the control cases, no background wind as well (i.e. local free convection). The surface roughness length, $z_{0}$, is set to $0.1 \mathrm{~m}$. The initial potential temperature profile is constant at $300 \mathrm{~K}$ in the boundary layer with a temperature jump of $0.8 \mathrm{~K}$ at $1000 \mathrm{~m}$. In the free troposphere, the potential temperature, $\theta$, rises by $6 \times 10^{-3} \mathrm{~K} \mathrm{~m}^{-1}$. The initial humidity profile, $q$, is set constant at $6 \times 10^{-3} \mathrm{~kg} \mathrm{~kg}^{-1}$ in the boundary layer and $3 \times 10^{-3} \mathrm{~kg} \mathrm{~kg}^{-1}$ in the free troposphere. The chosen humidity is lower than the characteristic values for the Amazonian rain forest to prevent cloud formation and maintain a clear boundary layer during the numerical experiments. The drawback of this choice is its impact on the $\mathrm{HO}_{\mathrm{x}}$ production. Consequently, the intensity of segregation for the isoprene- $\mathrm{OH}$ reaction is affected as well and quantitative results should be considered as first order estimates. The surface kinematic heat flux and moisture flux are set to $0.15 \mathrm{~K} \mathrm{~m} \mathrm{~s}^{-1}$ and $1 \times 10^{-4} \mathrm{~kg} \mathrm{~kg}^{-1} \mathrm{~m} \mathrm{~s}^{-1}$ respectively. This corresponds to a sensible heat flux of approximately $185 \mathrm{~W} \mathrm{~m}^{-2}$ and a latent heat flux of approximately $300 \mathrm{~W} \mathrm{~m}^{-2}$.

As well as a passive tracer, 18 reactant species are simulated in the numerical experiments. The applied chemical scheme contains the 19 essential reactions for the $\mathrm{O}_{3}-\mathrm{NO}_{\mathrm{x}}-$ VOC- $\mathrm{HO}_{\mathrm{x}}$ system during daytime in the Amazonian rain forest (Vilà-Guerau de Arellano et al., 2011) and is shown in 
Table 2. Chemical reaction scheme solved in the numerical experiments by the chemistry module of DALES (Vilà-Guerau de Arellano et al., 2011). $T$ is the absolute temperature in $\mathrm{K}$. The unit of first-order reaction rate coefficients is $\mathrm{s}^{-1}$ and that of second-order reaction rate coefficients is $\mathrm{cm}^{3} \mathrm{molec}^{-1} \mathrm{~s}^{-1}$. Reaction (R15) has a more difficult expression for its reaction rate*. Reactions (R1), (R5) and (R6) are photolysis reactions which only occur if photons interact with the reactants. REST stands for products and/or secondary fast reactions with reactants in the ambient air that are not directly evaluated.

\begin{tabular}{|c|c|c|c|}
\hline \multirow{2}{*}{$\begin{array}{r}\text { Name } \\
\text { R1 }\end{array}$} & \multicolumn{2}{|r|}{ Chemical equation } & \multirow{2}{*}{$\begin{array}{l}\text { Reaction rate constant } \\
6.62 \times 10^{-5} \cdot e^{-0.575}\end{array}$} \\
\hline & $\mathrm{O}_{3}+h v$ & $\rightarrow \quad \mathrm{O}^{1 \mathrm{D}}+\mathrm{O}_{2}$ & \\
\hline $\mathrm{R} 2$ & $\mathrm{O}^{1 \mathrm{D}}+\mathrm{H}_{2} \mathrm{O}$ & $\rightarrow \quad 2 \mathrm{OH}$ & $1.63 \times 10^{-10} \cdot e^{\frac{60}{T}}$ \\
\hline R3 & $\mathrm{O}^{1 \mathrm{D}}+\mathrm{N}_{2}$ & $\rightarrow \quad \mathrm{O}_{3}+\mathrm{REST}$ & $2.15 \times 10^{-11} \cdot e^{\frac{110}{T}}$ \\
\hline $\mathrm{R} 4$ & $\mathrm{O}^{1 \mathrm{D}}+\mathrm{O}_{2}$ & $\rightarrow \quad \mathrm{O}_{3}$ & $3.30 \times 10^{-11} \cdot e^{\frac{55}{T}}$ \\
\hline R5 & $\mathrm{NO}_{2}+h v$ & $\rightarrow \quad \mathrm{NO}+\mathrm{O}_{3}+\mathrm{REST}$ & $1.67 \times 10^{-2} \cdot e^{-0.575}$ \\
\hline R6 & $\mathrm{CH}_{2} \mathrm{O}+h v$ & $\mathrm{HO}_{2}+\mathrm{REST}$ & $5.88 \times 10^{-5} \cdot e^{-0.575}$ \\
\hline $\mathrm{R} 7$ & $\mathrm{OH}+\mathrm{CO}$ & $\rightarrow \quad \mathrm{HO}_{2}+\mathrm{CO}_{2}+\mathrm{REST}$ & $2.40 \times 10^{-13}$ \\
\hline R8 & $\mathrm{OH}+\mathrm{CH}_{4}$ & $\rightarrow \quad \mathrm{CH}_{3} \mathrm{O}_{2}+\mathrm{REST}$ & $2.45 \times 10^{-12} \cdot e^{\frac{-1775}{T}}$ \\
\hline R9 & $\mathrm{OH}+\mathrm{C}_{5} \mathrm{H}_{8}$ & $\rightarrow \quad \mathrm{RO}_{2}$ & $1.00 \times 10^{-10}$ \\
\hline $\mathrm{R} 10$ & $\mathrm{OH}+\mathrm{MVK}$ & $\rightarrow \quad \mathrm{HO}_{2}+\mathrm{CH}_{2} \mathrm{O}+\mathrm{REST}$ & $2.40 \times 10^{-11}$ \\
\hline R11 & $\mathrm{HO}_{2}+\mathrm{NO}$ & $\rightarrow \quad \mathrm{OH}+\mathrm{NO}_{2}$ & $3.50 \times 10^{-12} \cdot e^{\frac{250}{T}}$ \\
\hline $\mathrm{R} 12$ & $\mathrm{CH}_{3} \mathrm{O}_{2}+\mathrm{NO}$ & $\rightarrow \quad \mathrm{HO}_{2}+\mathrm{NO}_{2}+\mathrm{CH}_{2} \mathrm{O}+\mathrm{REST}$ & $2.80 \times 10^{-12} \cdot e^{\frac{300}{T}}$ \\
\hline $\mathrm{R} 13$ & $\mathrm{RO}_{2}+\mathrm{NO}$ & $\rightarrow \quad \mathrm{HO}_{2}+\mathrm{NO}_{2}+\mathrm{CH}_{2} \mathrm{O}+\mathrm{MVK}$ & $1.00 \times 10^{-11}$ \\
\hline R14 & $\mathrm{OH}+\mathrm{CH}_{2} \mathrm{O}$ & $\rightarrow \quad \mathrm{HO}_{2}+\mathrm{REST}$ & $5.50 \times 10^{-12} \cdot e^{\frac{125}{T}}$ \\
\hline $\mathrm{R} 15$ & $2 \mathrm{HO}_{2}$ & $\rightarrow \quad \mathrm{H}_{2} \mathrm{O}_{2}+\mathrm{O}_{2}$ & $k^{*}$ \\
\hline $\mathrm{R} 16$ & $\mathrm{CH}_{3} \mathrm{O}_{2}+\mathrm{HO}_{2}$ & $\rightarrow \quad$ REST & $4.10 \times 10^{-13} \cdot e^{\frac{750}{T}}$ \\
\hline $\mathrm{R} 17$ & $\mathrm{RO}_{2}+\mathrm{HO}_{2}$ & $\rightarrow \quad \mathrm{REST}$ & $1.50 \times 10^{-11}$ \\
\hline $\mathrm{R} 18$ & $\mathrm{OH}+\mathrm{NO}_{2}$ & $\rightarrow \quad \mathrm{HNO}_{3}$ & $3.50 \times 10^{-12} \cdot e^{\frac{340}{T}}$ \\
\hline R19 & $\mathrm{NO}+\mathrm{O}_{3}$ & $\rightarrow \quad \mathrm{NO}_{2}+\mathrm{O}_{2}$ & $3.00 \times 10^{-12} \cdot e^{-\frac{1500}{T}}$ \\
\hline
\end{tabular}

$* k=\left(k_{1}+k_{2}\right) k_{3}, k_{1}=2.2 \times 10^{-13} \cdot e^{\frac{600}{T}}, k_{2}=1.9 \times 10^{-33} \cdot e^{\frac{980}{T}} \cdot c_{\mathrm{air}}, k_{3}=1+1.4 \times 10^{-21} \cdot e^{\frac{2200}{T}} \cdot c_{\mathrm{H}_{2} \mathrm{O}}$

Table 2. Concentrations are converted from $\mathrm{ppb}$ to molec $\mathrm{cm}^{-3}$ before applying the chemical scheme and back afterwards. The simulated reactants correspond to the species listed in this scheme, although it should be noted that all first generation oxidation products of isoprene $\left(\mathrm{C}_{5} \mathrm{H}_{8}\right)$, through Reactions (R9) and (R13), are lumped into methyl vinyl ketone $(\mathrm{MVK})$. For 10 reactants the surface fluxes and initial concentrations are assumed to be 0 , but the other 9 reactants have non zero emissions or initial concentrations. $\mathrm{O}_{3}, \mathrm{CH}_{4}$, $\mathrm{CO}, \mathrm{O}_{2}$ and $\mathrm{N}_{2}$ are assigned initial concentrations over the whole domain of $10 \mathrm{ppb}, 1724 \mathrm{ppb}, 124 \mathrm{ppb}, 2 \times 10^{8} \mathrm{ppb}$ and $8 \times 10^{8} \mathrm{ppb}$, respectively. The initial concentrations of $\mathrm{NO}_{2}$ and MVK are $1 \mathrm{ppb}$ and $1.3 \mathrm{ppb}$ below the initial boundary layer height and both $0 \mathrm{ppb}$ in the free troposphere. The emission of $\mathrm{NO}$ is set to $5 \times 10^{-4} \mathrm{ppb} \mathrm{m} \mathrm{s}^{-1}$. For isoprene the emission is set to $0.65 \mathrm{ppb} \mathrm{m} \mathrm{s}^{-1}$ and the initial concentration profile is set to $2 \mathrm{ppb}$ in the boundary layer and $0 \mathrm{ppb}$ in the free troposphere. In this idealized setup $\mathrm{NO}_{\mathrm{x}}$ is not completely realistically represented. Sensitivity studies have shown that under the chosen set of conditions the $\mathrm{NO}_{\mathrm{x}}$ emissions have very limited impact on the isoprene-OH segregation. However, entrainment of $\mathrm{NO}_{\mathrm{x}}$ from the free troposphere can significantly alter the boundary layer chemistry as will be shown in Sect. 3.6.

As mentioned before, this study is based on two control cases: one with homogeneous and one with heterogeneous surface conditions. The control case with heterogeneous surface conditions is split into 4 patches in the $\mathrm{x}$-direction. The first and third patch correspond to a forest, while the second and fourth patch have typical savannah surface properties. Because of the periodic boundary conditions (i.e. opposing borders of the domain are connected) used by DALES, this configuration represents an infinite sequence of alternating forest and savannah patches. A scheme of the setup of the numerical experiments is shown in Fig. 1.

Over the whole domain the total emissions of reactants, moisture and heat are kept equal to the case with homogeneous surface conditions, and only the distribution is changed. Over the forested patch the kinematic moisture flux is enhanced from $1 \times 10^{-4} \mathrm{~kg} \mathrm{~kg}^{-1} \mathrm{~m} \mathrm{~s}^{-1}$ to $1.2 \times$ $10^{-4} \mathrm{~kg} \mathrm{~kg}^{-1} \mathrm{~m} \mathrm{~s}^{-1}$ due to extra evapotranspiration in the forest compared to the savannah. For compensation the kinematic moisture flux is decreased to $0.8 \times 10^{-4} \mathrm{~kg} \mathrm{~kg}^{-1} \mathrm{~m} \mathrm{~s}^{-1}$ for the savannah patch. These changes correspond to 


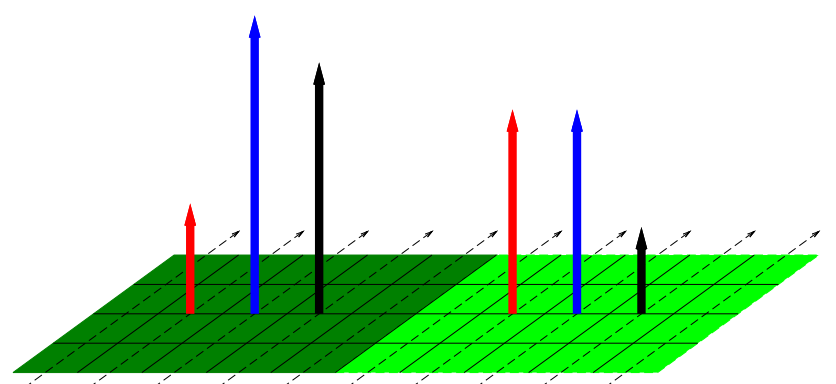

Fig. 1. Schematic overview of the heterogeneous surface conditions for the numerical experiments performed by DALES. The simulated domain is split into forest and savannah patches. Over the relatively cold and wet forest patch the sensible heat flux is lower than over the relatively warm and dry savannah patch, but the latent heat flux is higher. The emission of isoprene is highest over the forest. Over the whole domain the total isoprene emission and surface heat fluxes are kept the same as the case with homogeneous surface conditions. For both terrains the sum of the latent and sensible heat fluxes is the same. Generated statistics are averaged in the direction perpendicular to the direction of heterogeneity.

approximately $60 \mathrm{~W} \mathrm{~m}^{-2}$. To keep the total energy budget equal for both patches, the sum of sensible and latent heat fluxes is kept constant too. This results in a change of the kinematic heat flux to $0.1 \mathrm{~K} \mathrm{~m} \mathrm{~s}^{-1}$ for the forest patch and $0.2 \mathrm{~K} \mathrm{~m} \mathrm{~s}^{-1}$ for the savannah patch. The biogenic emission of isoprene over the forest patch is higher than over the savannah patch (Kesselmeier and Staudt, 1999; Garcia-Carreras et al., 2010). An emission of $1.0 \mathrm{ppb} \mathrm{m} \mathrm{s}^{-1}$ is set for the forest and $0.3 \mathrm{ppb} \mathrm{m} \mathrm{s}^{-1}$ for the savannah configuration. Other emissions and the initial concentration, temperature and specific humidity profiles are kept equal to the case with homogeneous surface conditions. As will be shown in Sect. 3.1.1, the changes in kinematic heat and moisture fluxes cause a difference in buoyancy flux between the forest and savannah patches. This difference generates mesoscale circulations in the xz-plane. To enable visualisation of these circulations and to study the different atmospheric conditions over the two terrain types, average statistics are calculated in the y-direction (Patton et al., 2005; van Heerwaarden and Vilà-Guerau de Arellano, 2008).

Next to the two control cases, we perform sensitivity analyses. These simulations are based on the control case with heterogeneous surface properties. An overview of all performed numerical experiments with their altered input variables is shown in Table 3. To study the influence of wind on the dynamics and chemistry, the large scale background wind profiles, $u_{g}$ and $v_{g}$ in $\mathrm{m} \mathrm{s}^{-1}$, are varied in Sect. 3.2. For some simulations the grid size is doubled in the $\mathrm{x}$-direction, resulting in a larger domain size. For these simulations, the total number of patches in which the surface is divided in the x-direction, $N_{\text {patches }}$, is varied to determine the impact of the length scale of heterogeneous surface properties. The odd numbered patches represent forest areas and the even numbered patches represent savannah. These results are discussed in Sect. 3.3. The dependence on the magnitude of the difference in emissions between the two land types is studied for heat fluxes and isoprene emissions separately. In Sect. 3.4 the difference in isoprene emission by the forest relative to the savannah, $\Delta E_{\text {isoprene, } f-s}$ in $\mathrm{ppb} \mathrm{m} \mathrm{s}^{-1}$, is varied. The sensitivity analysis presented in Sect. 3.5 treats the dependences on the differences between the forest and the savannah in kinematic heat flux, $\Delta{\overline{w^{\prime} \theta^{\prime}}}_{f-s}$ in $\mathrm{K} \mathrm{m} \mathrm{s}^{-1}$, and kinematic moisture flux, $\Delta{\overline{w^{\prime} q^{\prime}}}_{f-s}$ in $\mathrm{kg} \mathrm{kg}^{-1} \mathrm{~m} \mathrm{~s}^{-1}$. The impact of $\mathrm{NO}_{\mathrm{x}}$ is discussed in Sect. 3.6.

\subsection{Formulation and interpretation of the segregation}

We derive the intensity of segregation for a generic secondorder chemical reaction,

$A+B \rightarrow C$.

For a 3-dimensional field of filtered atmospheric variables, as generated by Large-Eddy Simulations, the concentration of a chemical compound $C$ satisfies the conservation equation

$\frac{\partial c_{C}}{\partial t}+\frac{\partial u_{i} c_{C}}{\partial x_{i}}+\mathrm{SGF}=R$

with

$R=k \cdot c_{A} \cdot c_{B}$.

$A, B$ and $C$ are indicators for chemical compounds, $u_{i}$ and $x_{i}$ are respectively the wind velocity and the coordinate in the $i$ direction, SGF is the parameterized sub-grid flux (see Heus et al. (2010) for a complete description), $k$ is the reaction constant, $R$ is the chemical reaction rate and $c_{A}, c_{B}$ and $c_{C}$ are the concentrations of respectively the chemicals $A, B$ and C.

Equations (1), (2) and (3) describe processes for a 3-D field. However, numerical calculations are often performed using spatially averaged values. In order to compare box models, mesoscale models or climate models with measurements, the averages for the 3-D field should be calculated over the complete mixing volume. Every possible variable, $\phi$, can be expressed as

$\phi=[\phi]+\phi^{\prime}$,

in which the rectangular brackets correspond to a spatial average and the prime corresponds to a deviation from the spatial average. The spatial average is calculated over a horizontal plane or over a volume. If the reaction rate constant is considered to be equal throughout the boundary layer, the spatial average of the reaction rate is equal to

$[R]=k \cdot\left[c_{A} \cdot c_{B}\right]$.

By applying a Reynolds decomposition (Eq. 4) with its properties, Eq. (5) becomes

$[R]=k \cdot\left(\left[c_{A}\right] \cdot\left[c_{B}\right]+\left[c_{A}^{\prime} \cdot c_{B}^{\prime}\right]\right)$. 
Table 3. Description of the different simulations. Variables not listed in this table are kept the same as the control cases treated in Sect. 2.2. $u_{g}$ and $v_{g}$ are the large scale background wind profiles. $N_{\text {patches }}$ represents the total number of patches in which the surface is divided in the x-direction. $\Delta \overline{w^{\prime} \theta^{\prime}} f-s$ is the difference in kinematic heat flux over the forest patch, $f$, relative to the savannah patch, $s$, and $\Delta \overline{w^{\prime} q^{\prime}} f-s$ is the difference in kinematic moisture flux. $\Delta E_{\text {isoprene, } f-s}$ represents the difference in isoprene emission between the forest and the savannah. $c_{\mathrm{NO}_{2}}$ is the initial free tropospheric $\mathrm{NO}_{2}$ concentration. The input variables that are altered with respect to the heterogeneous control numerical experiment, HET, are printed in bold.

\begin{tabular}{|c|c|c|c|c|c|c|c|c|}
\hline $\begin{array}{l}\text { Name } \\
{[-]}\end{array}$ & $\begin{array}{r}\text { Grid } \\
{[-x-x-]}\end{array}$ & {$\left[\mathrm{m} \mathrm{s}^{-1}\right]$} & {$\left[\mathrm{m} \mathrm{s}^{-1}\right]$} & $\begin{array}{r}\mathbf{N}_{\text {patches }} \\
{[-]}\end{array}$ & $\begin{array}{l}\Delta \overline{\mathbf{w}^{\prime} \theta^{\prime}} \mathbf{f}-\mathbf{s} \\
{\left[\mathrm{K} \mathrm{m} \mathrm{s}^{-1}\right]}\end{array}$ & $\begin{array}{r}\Delta \overline{\mathbf{w}^{\prime} \mathbf{q}_{\mathbf{f}}^{\prime}-\mathbf{s}} \\
{\left[10^{-3} \mathrm{~kg} \mathrm{~kg}^{-1} \mathrm{~m} \mathrm{~s}^{-1}\right]}\end{array}$ & $\begin{array}{r}\Delta \mathbf{E}_{\text {isoprene, }} \mathbf{f}-\mathbf{s} \\
\quad\left[\mathrm{ppb} \mathrm{m} \mathrm{s}^{-1}\right]\end{array}$ & $\begin{array}{l}\mathbf{c}_{\mathrm{NO}_{2}} \\
{[\mathrm{ppb}]}\end{array}$ \\
\hline \multicolumn{9}{|c|}{ Control numerical experiments } \\
\hline $\mathrm{HOM}$ & $256 \times 256 \times 128$ & 0.0 & 0.0 & 4 & 0.0000 & 0.000 & 0.0 & 0.0 \\
\hline HET & $256 \times 256 \times 128$ & 0.0 & 0.0 & 4 & -0.1000 & 0.040 & 0.7 & 0.0 \\
\hline \multicolumn{9}{|c|}{ Impact of background wind } \\
\hline WU1 & $256 \times 256 \times 128$ & 0.0 & 2.5 & 4 & 0.0000 & 0.000 & 0.0 & 0.0 \\
\hline WU2 & $256 \times 256 \times 128$ & 0.0 & 5.0 & 4 & 0.0000 & 0.000 & 0.0 & 0.0 \\
\hline WU3 & $256 \times 256 \times 128$ & 0.0 & 7.5 & 4 & 0.0000 & 0.000 & 0.0 & 0.0 \\
\hline WX1 & $256 \times 256 \times 128$ & 2.5 & 0.0 & 4 & -0.1000 & 0.040 & 0.7 & 0.0 \\
\hline WX2 & $256 \times 256 \times 128$ & 5.0 & 0.0 & 4 & -0.1000 & 0.040 & 0.7 & 0.0 \\
\hline WX3 & $256 \times 256 \times 128$ & 7.5 & 0.0 & 4 & -0.1000 & 0.040 & 0.7 & 0.0 \\
\hline WY1 & $256 \times 256 \times 128$ & 0.0 & 2.5 & 4 & -0.1000 & 0.040 & 0.7 & 0.0 \\
\hline WY2 & $256 \times 256 \times 128$ & 0.0 & 5.0 & 4 & -0.1000 & 0.040 & 0.7 & 0.0 \\
\hline WY3 & $256 \times 256 \times 128$ & 0.0 & 7.5 & 4 & -0.1000 & 0.040 & 0.7 & 0.0 \\
\hline \multicolumn{9}{|c|}{ Impact of the length scale of heterogeneity } \\
\hline LS1 & $256 \times 256 \times 128$ & 0.0 & 0.0 & 2 & -0.1000 & 0.040 & 0.7 & 0.0 \\
\hline LS2 & $256 \times 256 \times 128$ & 0.0 & 0.0 & 8 & -0.1000 & 0.040 & 0.7 & 0.0 \\
\hline LS3 & $256 \times 256 \times 128$ & 0.0 & 0.0 & 16 & -0.1000 & 0.040 & 0.7 & 0.0 \\
\hline LSB1 & $\mathbf{1 0 2 4} \times \mathbf{5 1 2} \times 128$ & 0.0 & 0.0 & 4 & 0.0000 & 0.0000 & 0.7 & 0.0 \\
\hline LSB2 & $\mathbf{1 0 2 4} \times \mathbf{5 1 2} \times 128$ & 0.0 & 0.0 & 2 & -0.1000 & 0.040 & 0.7 & 0.0 \\
\hline LSB3 & $\mathbf{1 0 2 4} \times \mathbf{5 1 2} \times 128$ & 0.0 & 0.0 & 4 & -0.1000 & 0.040 & 0.7 & 0.0 \\
\hline LSB4 & $1024 \times 512 \times 128$ & 0.0 & 0.0 & 8 & -0.1000 & 0.040 & 0.7 & 0.0 \\
\hline LSB5 & $\mathbf{1 0 2 4} \times \mathbf{5 1 2} \times 128$ & 0.0 & 0.0 & 16 & -0.1000 & 0.040 & 0.7 & 0.0 \\
\hline \multicolumn{9}{|c|}{ Impact of the spatial variation of isoprene emissions } \\
\hline IS1 & $256 \times 256 \times 128$ & 0.0 & 0.0 & 4 & -0.1000 & 0.040 & 1.3 & 0.0 \\
\hline IS2 & $256 \times 256 \times 128$ & 0.0 & 0.0 & 4 & -0.1000 & 0.040 & $\mathbf{0 . 0}$ & 0.0 \\
\hline IS3 & $256 \times 256 \times 128$ & 0.0 & 0.0 & 4 & -0.1000 & 0.040 & -0.7 & 0.0 \\
\hline \multicolumn{9}{|c|}{ Impact of the spatial variation of surface heat fluxes } \\
\hline HF1 & $256 \times 256 \times 128$ & 0.0 & 0.0 & 4 & 0.0000 & 0.000 & 0.7 & 0.0 \\
\hline HF2 & $256 \times 256 \times 128$ & 0.0 & 0.0 & 4 & -0.0125 & 0.005 & 0.7 & 0.0 \\
\hline HF3 & $256 \times 256 \times 128$ & 0.0 & 0.0 & 4 & -0.0250 & 0.010 & 0.7 & 0.0 \\
\hline HF4 & $256 \times 256 \times 128$ & 0.0 & 0.0 & 4 & -0.0375 & 0.015 & 0.7 & 0.0 \\
\hline HF5 & $256 \times 256 \times 128$ & 0.0 & 0.0 & 4 & -0.0500 & 0.020 & 0.7 & 0.0 \\
\hline HF6 & $256 \times 256 \times 128$ & 0.0 & 0.0 & 4 & -0.1500 & 0.060 & 0.7 & 0.0 \\
\hline HF7 & $256 \times 256 \times 128$ & 0.0 & 0.0 & 4 & -0.2000 & 0.080 & 0.7 & 0.0 \\
\hline \multicolumn{9}{|c|}{ Sensitivity to free tropospheric $\mathrm{NO}_{2}$} \\
\hline UNO & $256 \times 256 \times 128$ & 0.0 & 0.0 & 4 & 0.0000 & 0.000 & 0.0 & 0.5 \\
\hline $\mathrm{HNO}$ & $256 \times 256 \times 128$ & 0.0 & 0.0 & 4 & -0.1000 & 0.040 & 0.7 & 0.5 \\
\hline
\end{tabular}


The physical interpretation of the intensity of segregation is the relative deviation of the total chemical reaction rate from the reaction rate due to the mean concentrations,

$R_{\text {mean }}=k \cdot\left[c_{A}\right] \cdot\left[c_{B}\right]$.

This is expressed as

$I_{\mathrm{S}} \equiv \frac{[R]-R_{\text {mean }}}{R_{\text {mean }}}$.

$I_{\mathrm{S}}$ is the intensity of segregation. Substituting Eqs. (6) and (7) in Eq. (8) yields

$I_{\mathrm{S}}=\frac{\left[c_{A}^{\prime} \cdot c_{B}^{\prime}\right]}{\left[c_{A}\right] \cdot\left[c_{B}\right]}$

and the average chemical reaction rate reads:

$[R]=k \cdot\left(1+I_{\mathrm{S}}\right) \cdot\left[c_{A}\right] \cdot\left[c_{B}\right]=k_{\mathrm{eff}} \cdot\left[c_{A}\right] \cdot\left[c_{B}\right]$.

Equation (9) shows that the intensity of segregation is equal to the covariance of the two reacting chemicals divided by their mean concentrations. Since DALES explicitly resolves turbulence, including quantities like covariances, the intensities of segregation are calculated directly. Ouwersloot et al. (2010) validated the DALES results, confirming the dependence of segregation on the ratio of the turbulent time scale versus the chemical time scales and on the reactant concentration ratio (Schumann, 1989) and giving results in agreement with measurements (Butler et al., 2008; Dlugi et al., 2010) and previous simulations (Krol et al., 2000; Vinuesa and Vilà-Guerau de Arellano, 2003).

We further discuss the dependence of the intensity of segregation on the physical and chemical processes. For instance, for perfectly mixed conditions $I_{\mathrm{S}}$ is 0 , though its value can range from -1 to infinity. More insight on the sign of the intensity of segregation is obtained by analysing $I_{\mathrm{S}}$ as a function of the correlation and the concentration variances. The intensity of segregation for 2 reacting species is related with the correlation factor, $r$, where

$r=\frac{\sigma_{A B}}{\sigma_{A} \cdot \sigma_{B}}$.

The standard deviations of the concentrations of compounds $A$ and $B$ are expressed by $\sigma_{A}$ and $\sigma_{B}$ and their covariance is expressed by $\sigma_{A B}$. The variance of $c_{A}$ is defined as $\sigma_{A}^{2}=$ $\left[c_{A}^{\prime} \cdot c_{A}^{\prime}\right]$ and the covariance between $c_{A}$ and $c_{B}$ is equal to $\left[c_{A}^{\prime} \cdot c_{B}^{\prime}\right]$. Equations (9) and (11) show that

$I_{\mathrm{S}}=r \cdot \frac{\sigma_{A} \cdot \sigma_{B}}{\left[c_{A}\right] \cdot\left[c_{B}\right]}$.

This can be denoted as

$I_{\mathrm{S}}=r \cdot i_{A} \cdot i_{B}$,

where $i_{X}$ is the concentration fluctuation intensity of compound $X$, defined as

$i_{X} \equiv \frac{\sigma_{X}}{\left[c_{X}\right]}$.
Since concentrations and standard deviations are always positive if non-zero, the sign of $I_{\mathrm{S}}$ equals the sign of $r$. This correlation factor is controlled by transport and chemistry. First we will briefly address the influence of transport. Inert species that are transported together are positively correlated, $r>0$. This is the case for two compounds which are both entrained from the free troposphere or both emitted from the surface. If one compound is emitted from the surface and the other is entrained from the free troposphere, then the species are negatively correlated, $r<0$. Further, chemistry has an impact on the correlation factor since two reacting compounds are negatively correlated. For two reactants that are transported, the overall sign of the correlation factor therefore depends on the interaction between the dynamics and chemistry. The correlation between isoprene and $\mathrm{OH}$ as a function of height will be treated in Sect. 3.1.3.

\subsubsection{Definition of the boundary layer height}

To calculate the intensities of segregation in the boundary layer, the boundary layer height needs to be defined. For a heterogeneous surface forcing, it varies over the domain. In order to determine the boundary layer heights as a function of time and the x-coordinate, an adaptation of the maximum gradient method (Sullivan et al., 1998) is applied to the averages in the y-direction of the virtual potential temperature, $\theta_{v}$ :

$\theta_{v}=\theta \cdot(1+0.61 \cdot q)$

Differences in $\theta_{v}$ between air parcels and the air surrounding them drive the buoyancy (Stull, 1988). The buoyancy flux in a clear boundary layer is

$\overline{w^{\prime} \theta_{v}^{\prime}} \cong(1+0.61 \bar{q}) \overline{w^{\prime} \theta^{\prime}}+0.61 \bar{\theta} \overline{w^{\prime} q^{\prime}}$,

emphasizing the importance of the surface energy partitioning into sensible heat and moisture flux for buoyancy. Considering the difference in orders of magnitude of the different terms, this equation shows that the buoyancy flux is dominated by the kinematic sensible heat flux, $\overline{w^{\prime} \theta^{\prime}}$. Note that in the case of a uniform sensible surface heat flux, differences in the kinematic surface moisture flux, $\overline{w^{\prime} q^{\prime}}$, result in buoyancy flux differences and the generation of turbulence and mesoscale circulations. Hence, analyses that only take into account the amplitude of the sensible surface heat flux heterogeneity would be erroneous.

Mesoscale circulations lead to advection of warm air at the top of the boundary layer over a patch with relatively cool air. This results in a virtual potential temperature profile as shown in Fig. 2a. It shows the initial profile together with a profile after half an hour of simulation. The location is an arbitrary position in the area towards which warm air is advected. In the inversion zone, $z \approx 1000 \mathrm{~m}$, no clear $\theta_{v}$ gradient is present. This would result in a flawed determination of the boundary layer height using the maximum gradient method. To circumvent this, an alternative method is 

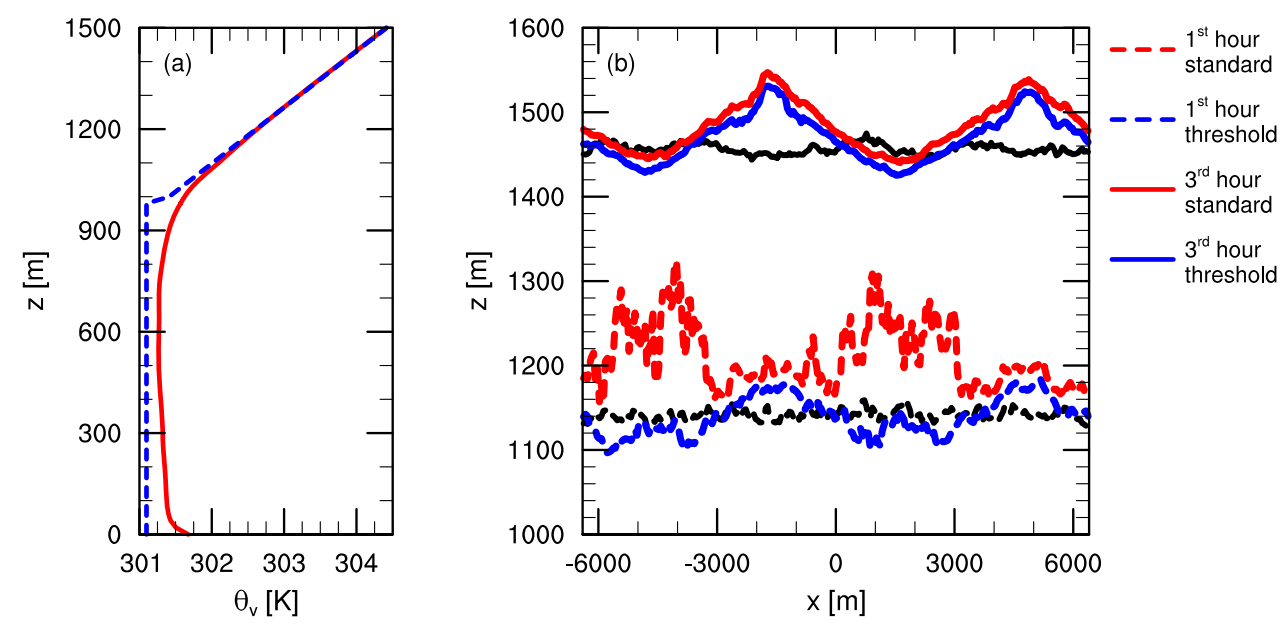

Fig. 2. (a) The initial profile in blue and the profile after $30 \mathrm{~min}$ in red for the virtual potential temperature as a function of height. The profile is calculated for an arbitrary position in the area towards which warm air is advected in the top of the boundary layer. In (b) the boundary layer heights as determined by the maximum gradient and the threshold gradient methods are shown as a function of the $\mathrm{x}$ position in respectively red and blue. As a reference, the boundary layer height over a homogeneous surface, as determined by the maximum gradient method, is shown in black. The dashed and solid lines show the boundary layer heights averaged over the first and third hour of the simulation, respectively. The relatively cold forest patches are located at $-6400 \mathrm{~m}<x<-3200 \mathrm{~m}$ and $0 \mathrm{~m}<x<3200 \mathrm{~m}$. Here, the boundary layer is shallower than over the relatively warm savannah patches.

proposed: a threshold gradient method. This method sets the boundary layer height equal to the lowest height for which the gradient of the considered variable, in our case the virtual potential temperature, exceeds a certain percentage of the maximum gradient. In the case no sharp inversion is present, this maximum gradient will be equal to the lapse rate in the free troposphere. In the treatment of the numerical experiments presented in this paper, the threshold percentage is set to $90 \%$. This threshold percentage is chosen such that the erratic boundary layer height determinations are suppressed, but the determined heights for profiles with a clear inversion remain similar. The result is shown in Fig. 2b. This graph is based on the numerical experiment HET. During the first hour the threshold gradient method results in smoother and less random boundary layer heights as a function of the $\mathrm{x}$ position. In the third hour the gradient is more well defined at all locations and both methods result in similar boundary layer heights.

\section{Results}

The main properties of the numerical experiments during the fourth hour of simulated time are summarized in Table 4 . The dynamical properties include the boundary layer height, the averages over the whole boundary layer of the potential temperature and the specific humidity, and the convective velocity scale. The convective velocity scale is almost unaffected by the differences between the numerical experiments. The listed chemical properties represent the volume averages of the isoprene and hydroxyl radical concentrations over the entire boundary layer and the intensity of segregation of the isoprene- $\mathrm{OH}$ reaction. The mean concentration of $\mathrm{OH}$ is less strongly affected by the differences between the simulations compared to the intensity of segregation and the mean isoprene concentration. A more detailed analysis of the results follows in the next paragraphs.

\subsection{Influence of heterogeneous surface conditions}

\subsubsection{Dynamics}

In Fig. 3, the dynamical characteristics are shown for the cases with standard homogeneous, HOM, and standard heterogeneous, HET, surface forcing. The savannah patches are located at $-\frac{\lambda}{2}<x<0$ and $\frac{\lambda}{2}<x<1$. The depicted variables are averaged both over the fourth hour of the numerical experiments ( $1 \mathrm{~h}$ average) and over the y-coordinate, which is the horizontal direction perpendicular to the direction of heterogeneity. The flow of air within the boundary layer is indicated by the arrows in Fig. 3a and b. From these graphs it is clear that a heterogeneous surface forcing influences the mixing in the atmospheric boundary layer. While the potential temperature and specific humidity are well-mixed throughout the boundary layer for the homogeneous case, a mesoscale structure appears for the heterogeneous case. The differences in surface buoyancy fluxes between the forest and savannah patches induce mesoscale circulations. Over the warm and dry savannah patches air is transported to the top of the boundary layer, while air is transported downward over 
Table 4. Main properties of the different numerical experiments averaged over the fourth hour of simulated time. $h_{\mathrm{BL}}$ represents the boundary layer height. $\langle\theta\rangle$ and $\langle q\rangle$ are respectively the potential temperature and specific humidity averaged over the whole boundary layer. $w_{*}$ is the convective velocity scale. The boundary layer averaged concentrations of isoprene and $\mathrm{OH}$ are denoted by respectively $\left\langle c_{\text {Isoprene }}\right\rangle$ and $\left\langle c_{\mathrm{OH}}\right\rangle$. Is $\mathrm{R}_{\mathrm{R}}$ is the intensity of segregation for Reaction (R9) (Table 2).

\begin{tabular}{lrrrrrrr}
\hline $\begin{array}{l}\text { Case } \\
{[-]}\end{array}$ & $\begin{array}{r}h_{B L} \\
{[\mathrm{~m}]}\end{array}$ & $\begin{array}{r}\langle\mathrm{K}] \\
{[\mathrm{K}]}\end{array}$ & $\begin{array}{r}\langle q\rangle \\
{\left[10^{-3} \mathrm{~kg} \mathrm{~kg}^{-1}\right]}\end{array}$ & $\begin{array}{r}w_{*} \\
{\left[\mathrm{~m} \mathrm{~s}^{-1}\right]}\end{array}$ & $\begin{array}{r}\left\langle c_{\text {Isoprene }}\right\rangle \\
{[\mathrm{ppb}]}\end{array}$ & $\begin{array}{r}\left\langle c_{\mathrm{OH}}\right\rangle \\
{[\mathrm{ppt}]}\end{array}$ & $\begin{array}{r}\mathrm{Is}_{\mathrm{R} 9} \\
{[-]}\end{array}$ \\
\hline HOM & 1550 & 302.11 & 5.74 & 2.04 & 1.28 & 0.142 & -0.070 \\
HET & 1587 & 302.16 & 5.68 & 2.05 & 1.33 & 0.142 & -0.126 \\
WU1 & 1538 & 302.10 & 5.76 & 2.03 & 1.30 & 0.142 & -0.077 \\
WU2 & 1528 & 302.08 & 5.78 & 2.03 & 1.32 & 0.142 & -0.087 \\
WU3 & 1527 & 302.08 & 5.78 & 2.03 & 1.32 & 0.142 & -0.093 \\
WX1 & 1534 & 302.09 & 5.77 & 2.03 & 1.34 & 0.143 & -0.110 \\
WX2 & 1529 & 302.09 & 5.77 & 2.03 & 1.33 & 0.142 & -0.104 \\
WX3 & 1530 & 302.09 & 5.77 & 2.03 & 1.33 & 0.142 & -0.104 \\
WY1 & 1587 & 302.16 & 5.68 & 2.05 & 1.33 & 0.142 & -0.132 \\
WY2 & 1576 & 302.15 & 5.69 & 2.05 & 1.35 & 0.142 & -0.143 \\
WY3 & 1576 & 302.15 & 5.69 & 2.05 & 1.37 & 0.143 & -0.154 \\
LS1 & 1557 & 302.12 & 5.73 & 2.04 & 1.42 & 0.143 & -0.176 \\
LS2 & 1606 & 302.19 & 5.64 & 2.06 & 1.29 & 0.142 & -0.114 \\
LS3 & 1568 & 302.14 & 5.71 & 2.05 & 1.30 & 0.141 & -0.090 \\
LSB1 & 1549 & 302.11 & 5.74 & 2.04 & 1.28 & 0.142 & -0.070 \\
LSB2 & 1528 & 302.11 & 5.78 & 2.03 & 1.61 & 0.168 & -0.405 \\
LSB3 & 1547 & 302.12 & 5.75 & 2.04 & 1.54 & 0.153 & -0.308 \\
LSB4 & 1552 & 302.12 & 5.74 & 2.04 & 1.43 & 0.143 & -0.177 \\
LSB5 & 1587 & 302.16 & 5.68 & 2.06 & 1.33 & 0.142 & -0.126 \\
IS1 & 1587 & 302.16 & 5.68 & 2.05 & 1.41 & 0.142 & -0.183 \\
IS2 & 1587 & 302.16 & 5.68 & 2.05 & 1.28 & 0.142 & -0.087 \\
IS3 & 1587 & 302.16 & 5.68 & 2.05 & 1.30 & 0.141 & -0.095 \\
HF1 & 1550 & 302.11 & 5.74 & 2.04 & 1.43 & 0.145 & -0.196 \\
HF2 & 1546 & 302.11 & 5.75 & 2.04 & 1.41 & 0.141 & -0.148 \\
HF3 & 1545 & 302.10 & 5.75 & 2.04 & 1.38 & 0.140 & -0.114 \\
HF4 & 1548 & 302.11 & 5.75 & 2.04 & 1.36 & 0.140 & -0.110 \\
HF5 & 1556 & 302.12 & 5.73 & 2.04 & 1.35 & 0.141 & -0.111 \\
HF6 & 1622 & 302.21 & 5.62 & 2.07 & 1.32 & 0.142 & -0.146 \\
HF7 & 1650 & 302.26 & 5.58 & 2.08 & 1.33 & 0.143 & -0.174 \\
UNO & 1550 & 302.11 & 5.74 & 2.04 & 1.04 & 0.192 & -0.124 \\
HNO & 1587 & 302.16 & 5.68 & 2.05 & 1.10 & 0.197 & -0.209 \\
\hline & & & & & & &
\end{tabular}

the colder and wetter forested patches. This is in accord with the findings of Patton et al. (2005) and van Heerwaarden and Vilà-Guerau de Arellano (2008). The rising air moves faster (with a velocity of more than $2 \mathrm{~m} \mathrm{~s}^{-1}$ in the core of the rising plume halfway up the boundary layer) and is spread over a smaller area than the descending air (with an average velocity of approximately $0.5 \mathrm{~m} \mathrm{~s}^{-1}$ halfway up the boundary layer). Due to this pattern, turbulent mixing is stronger over the savannah patches than over the forest patches.

For the heterogeneous case the average boundary layer height is higher than for the homogeneous case, but also more variability is observed in the $\mathrm{x}$-direction. This effect is explained by van Heerwaarden and Vilà-Guerau de Arellano (2008). At the top of the buoyant thermals, the entrainment is enhanced, because the relatively warm air with more kinetic energy can penetrate the inversion layer relatively easily.
The entrained air is horizontally advected towards the forest patches where it is transported downwards. Over the forest patches, thermals are suppressed by the subsiding branch of the mesoscale circulations, reducing entrainment over these areas. This process leads to higher boundary layer heights over the savannah patches than over the forest patches. The average boundary layer height of the numerical experiment HET is higher than that of HOM, however this difference is less than $40 \mathrm{~m}$. The minimum boundary layer height in the numerical experiment HET is approximately equal to the average boundary layer height in the numerical experiment HOM. A more detailed explanation of the dependence of the boundary layer height on the surface energy partitioning is presented in Sect. 3.5.

The right panels of Fig. 3 show that the variability of the dynamic variables in the $\mathrm{x}$-direction is increased significantly 

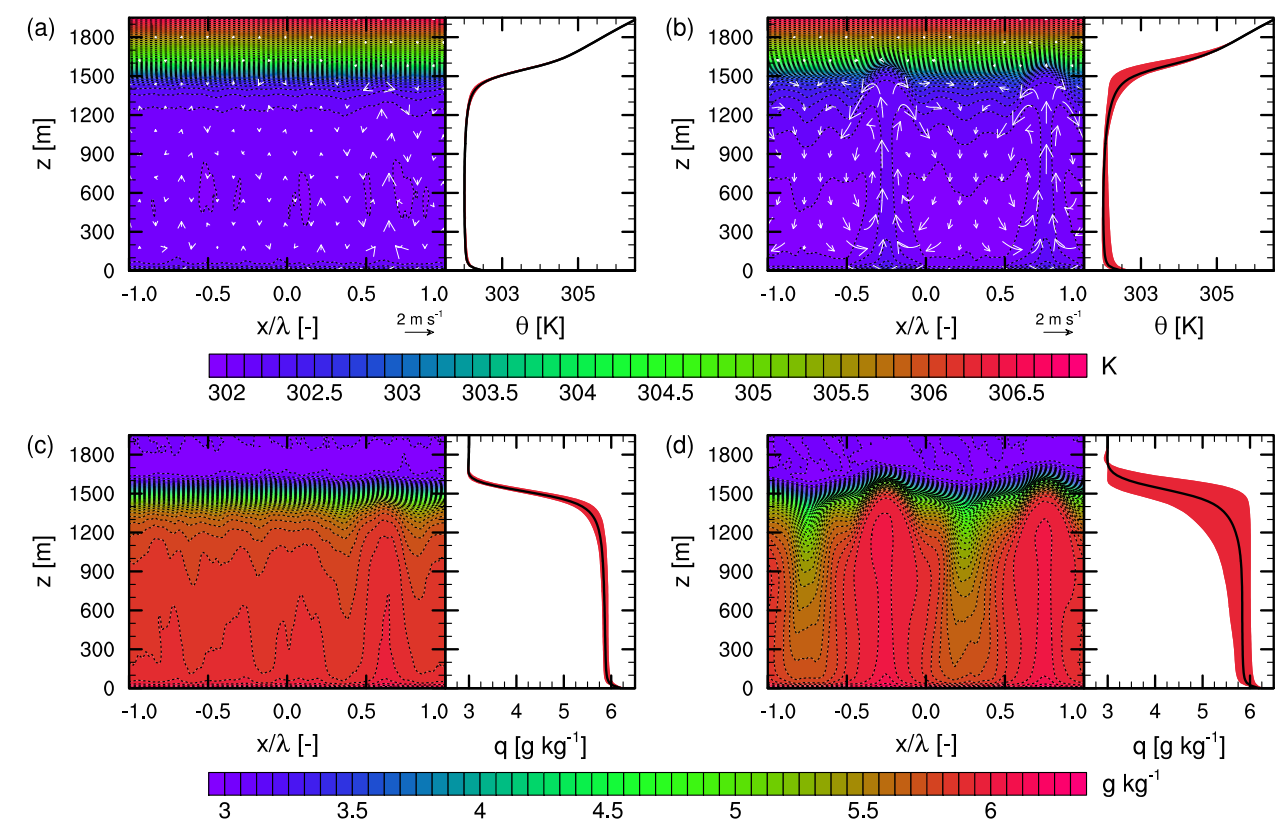

Fig. 3. Potential temperature and moisture for the homogeneous case $(\mathbf{a}, \mathbf{c})$ and the heterogeneous case (b, d). Each figure consists of two panels. The first panel shows these variables averaged over the fourth hour of simulated time and the y-direction, while the second panel shows an additional average in the $\mathrm{x}$-direction. The red area in the second panel shows the variability in the $\mathrm{x}$-direction of the temporal and y averaged values. The potential temperature, $\theta$, is shown on top $(\mathbf{a}, \mathbf{b})$ and the specific humidity, $q$, at the bottom (c, d). Wind direction and magnitude are indicated by vectors $(\mathbf{a}, \mathbf{b})$. The $\mathrm{x}$-coordinate is scaled by the length scale of heterogeneity, $\lambda$, which is twice the patch size.

by a heterogeneous surface forcing. This is caused by entrained air and the mesoscale circulations. In the lower half of the boundary layer, the air over the savannah is warmer due to the higher sensible heat fluxes. The mesoscale circulations caused by this difference transport emitted moisture from the forest to the savannah. Therefore the air over the savannah, which is transported upward, is warmer and more moist than over the forest. In the upper half of the boundary layer, entrainment is of importance. The entrained air is warmer and drier than the air in the boundary layer and is transported to the forest patch by a mesoscale circulation. Therefore, also the air in the upper half of the boundary layer is drier over the forested patch than over the savannah patch. However, due to the relatively warm air parcels that are entrained, the temperature in the upper half of the boundary layer is higher over the forest patch than over the savannah patch. The processes near the surface and the entrainment zone have the same effect on the horizontal distribution of moisture in the boundary layer, while the effects are opposed for the distribution of the potential temperature. Because of this, the variability in the potential temperature is much lower than the variability in the specific humidity if normalized by the differences between the free troposphere and the boundary layer for the respective variables.

In contrast to the increased variability of the dynamic variables, the horizontally averaged vertical profiles are very similar. The maximum differences in potential temperature and specific humidity are located at approximately $1350 \mathrm{~m}$ and $1600 \mathrm{~m}$ height, which are, respectively, in the upper part and just above the average top of the boundary layer. For the heterogeneous case the potential temperature at these heights are respectively $0.1 \mathrm{~K}$ warmer and $0.3 \mathrm{~K}$ colder, while the specific humidity at these heights are respectively $0.1 \mathrm{~g} \mathrm{~kg}^{-1}$ lower and $0.3 \mathrm{~g} \mathrm{~kg}^{-1}$ higher. The small decrease in average potential temperature and the small increase in specific humidity for the heterogeneous surface forcing are due to the intrusion of the buoyant thermals towards the free troposphere. Since the air in the boundary layer is more humid and colder than the free troposphere, this leads to the deviation in averaged quantities. The changes at a height of $1350 \mathrm{~m}$ are due to entrained air from the free troposphere.

\subsubsection{Atmospheric chemistry}

The spatial distributions of the concentrations and reaction rates of isoprene with the hydroxyl radical are displayed in Fig. 4 for the numerical experiments HOM and HET. As we specifically study the isoprene-OH reaction, the concentrations of these two reactants are shown together with their chemical reaction rate. Due to the induced mesoscale circulations, the isoprene is advected near the earth's surface from the forest towards the savannah patches, where it is transported upwards. After emission, the isoprene reacts with $\mathrm{OH}$. Due to these interactions, above the surface layer the 
(a)

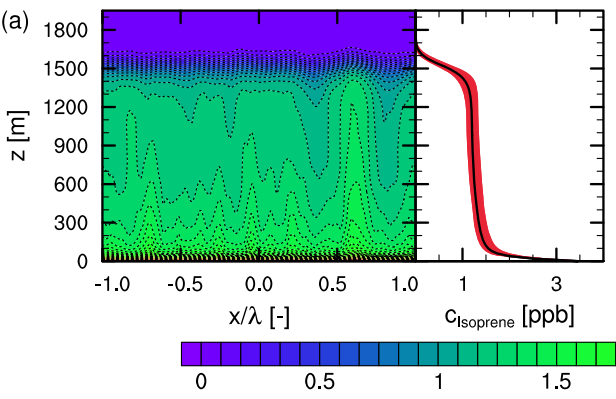

(c)

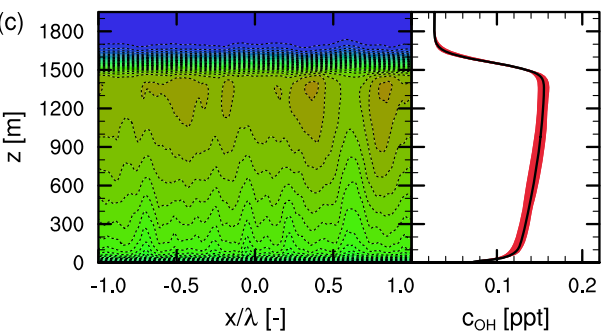

(b) 1800

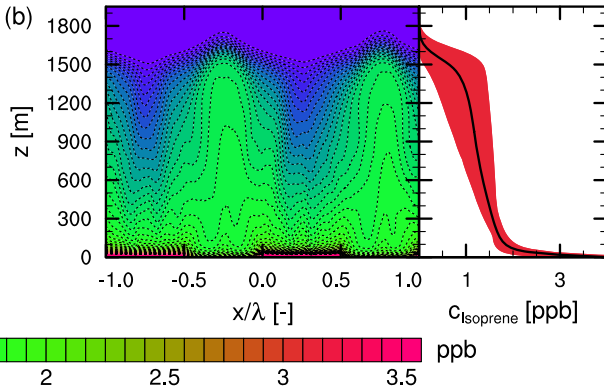

(d) 1800

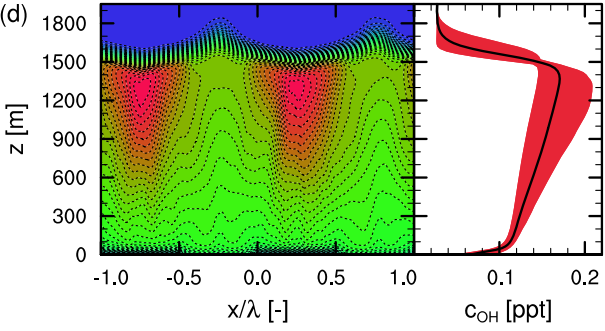

$$
0
$$

0.04

0.08

\subsection{2}

0.16

0.2
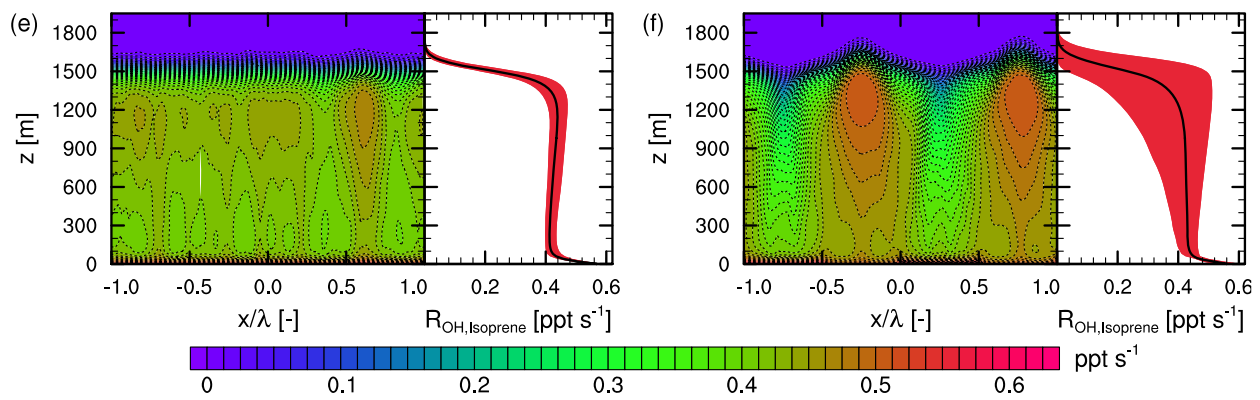

Fig. 4. Isoprene and $\mathrm{OH}$ concentrations and chemical reaction rates for the homogeneous case (a, $\mathbf{c}, \mathbf{e})$ and the heterogeneous case (b, $\mathbf{d}, \mathbf{f})$. Each figure consists of two panels. The first panel shows these variables averaged over the fourth hour of simulated time and the y-direction, while the second panel shows an additional average in the $\mathrm{x}$-direction. The red area in the second panel shows the variability in the $\mathrm{x}$-direction

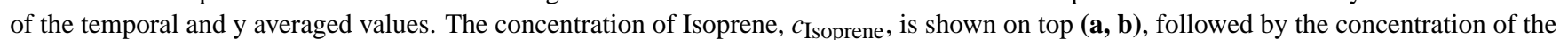
hydroxyl radical, $c_{\mathrm{OH}}$, in the middle $(\mathbf{c}, \mathbf{d})$. At the bottom $(\mathbf{e}, \mathbf{f})$ the chemical reaction rates for Reaction $(\mathrm{R} 9), R_{\mathrm{OH}, \mathrm{Isoprene}}$, are displayed. The $\mathrm{x}$-coordinate is scaled by the length scale of heterogeneity, $\lambda$, which is twice the patch size.

concentration of isoprene is significantly higher over the savannah patches than over the forested patches. This is shown in more detail in Fig. 5. Since isoprene depletes $\mathrm{OH}$, the chemical reaction rates are highest and the $\mathrm{OH}$ concentrations are lowest over the savannah patches. At the top of the rising thermals a region appears with a relatively high reaction rate, because the chemical reaction rate depends on the product of both concentrations. These features are governed by the spatial distribution of isoprene. Dynamics have an impact on chemistry, because in the thermals the lifetime of isoprene (approximately $50 \mathrm{~min}$ ) is of the same order of magnitude as the transport time from the surface to the top of the boundary layer (approximately $15 \mathrm{~min}$ ). For both the homogeneous and heterogeneous surface forcings the reaction rate is highest near the surface, where isoprene concentrations are highest.
Due to the mesoscale circulations, the boundary layer over the forest is strongly influenced by the entrained air, while the boundary layer over the savannah is mainly affected by the surface turbulent fluxes. Therefore, a heterogeneous surface forcing leads to an enhancement of the variability of the chemical variables. In addition, the mean variables as a function of height, shown in the right panels of Fig. 4, as well as the averages over the entire domain are affected. For the uniform surface forcing the relatively long-lived species like isoprene are well-mixed, which results in a concentration that is approximately constant with height. However, for a heterogeneous surface forcing the slope of the isoprene concentration profile with height is strongly enhanced due to the entrained air that is transported towards the forested areas. Over the forest, turbulent mixing is less effective for a heterogeneous surface forcing, which results in a significant concentration gradient. Since $\mathrm{OH}$ is depleted by isoprene, 

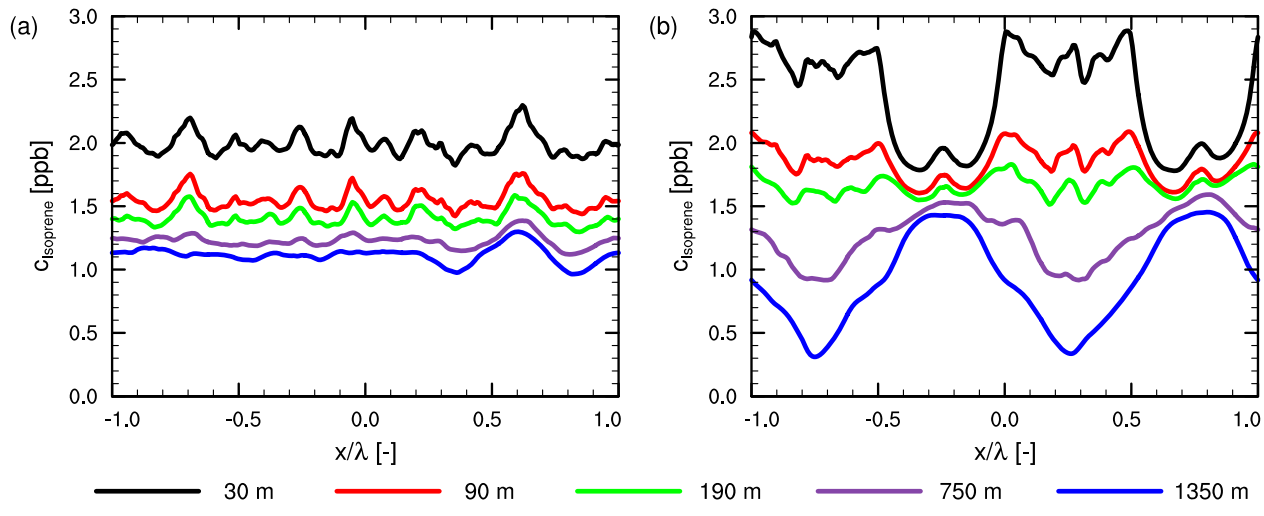

Fig. 5. Isoprene concentrations for the homogeneous case (a) and the heterogeneous case (b) at different heights. The concentrations are averaged over the fourth hour of simulated time and the $y$-direction. The $x$-coordinate is scaled by the length scale of heterogeneity, $\lambda$, which is twice the patch size. The forest patches are located at $-1<\frac{x}{\lambda}<-0.5$ and $0<\frac{x}{\lambda}<0.5$ and the savannah patches are located elsewhere.

also the $\mathrm{OH}$ concentration profile is influenced by this process. The altered concentration profiles result in a differently shaped profile of the isoprene- $\mathrm{OH}$ reaction rate. The average concentrations over the entire domain are enhanced by $1.3 \%$ and $5.1 \%$ for $\mathrm{OH}$ and isoprene, respectively, while the resulting average chemical reaction rate is reduced by $0.68 \%$. This counter-intuitive combination of effects that shows a nonlinear response, is caused by increased segregation $\left(1+I_{\mathrm{S}}\right.$ over the entire domain is decreased by $6.7 \%$ ), as outlined in Sect. 2.3.

Figure 4 shows that the $y$-averages of the concentrations of $\mathrm{OH}$ and isoprene as well as the chemical reaction rate vary both in the x-direction and in height. To calculate the average reaction rate, the different rates have to be determined locally and then averaged spatially, as shown in Eq. (5). For this calculation spatially averaged concentrations cannot be used without knowledge of the covariance of the reacting species (Eq. 6). This poses a problem for the interpretation of observations that cover only one point in space at a time, e.g. aircraft observations. To interpret these data, one needs to know the intensity of segregation or perform simultaneous observations of all relevant reactants at a high frequency in order to determine the covariances between those reactants.

\subsubsection{Processes driving segregation}

For the numerical experiments HOM and HET the intensities of segregation in the boundary layer during the 4th hour are -0.07 and -0.13 , respectively. This corresponds to effective chemical reaction rates ( $k_{\text {eff }}$ in Eq. 10) of $93 \%$ and $87 \%$ compared to the chemical reaction rates that are calculated from boundary layer averaged concentrations. This shows that atmospheric chemistry is influenced by dynamics and that a heterogeneous surface forcing might enhance this influence. In this section the processes that drive the segregation are explored.
The intensity of segregation profiles, for the reaction in which $\mathrm{OH}$ and isoprene form $\mathrm{RO}_{2}$, are shown in Fig. 6a, b. To produce this figure, the instantaneous intensities of horizontal segregation are determined for each height at $1 \mathrm{~min}$ intervals. The mean and variability for these profiles during the fourth hour are depicted with the solid lines and shading. The dashed lines represent the averages over the fourth hour of the instantaneous intensities of segregation over the entire boundary layer at $1 \mathrm{~min}$ intervals. Since the intensity of segregation is used to relate the boundary layer averaged chemical reaction rate to the reaction rate which would be calculated using boundary layer averaged concentrations, the intensities of segregation over the entire boundary layer are of most interest. However, the profiles of the intensities of horizontal segregation enable us to identify processes driving the segregation.

Figure $6 \mathrm{a}$ and $\mathrm{b}$ show that the average horizontal segregation can be divided into 3 regions. The lowest region is the surface layer in which the intensity is most negative. Near the top of the boundary layer, the intensity of segregation increases to large positive values. The largest region is inbetween, representing the bulk value of the intensity of horizontal segregation. The intensities differ from each other and all are different from the intensity of total boundary layer segregation.

To understand these profiles, the two terms of Eq. (12) are plotted separately in Fig. $6 \mathrm{c}$ and e for the numerical experiment HOM and in Fig. $6 \mathrm{~d}$ and $\mathrm{f}$ for the numerical experiment HET. It is shown that for both numerical experiments the horizontal correlation factors behave similar. In the boundary layer, isoprene and the hydroxyl radical are almost perfectly anti-correlated. This indicates that the correlation is strongly influenced by chemistry (Reaction R9). For the heterogeneous surface forcing this anti-correlation is lower in the lower part of the boundary layer. This is probably caused by the generation of regions characterized by low isoprene 

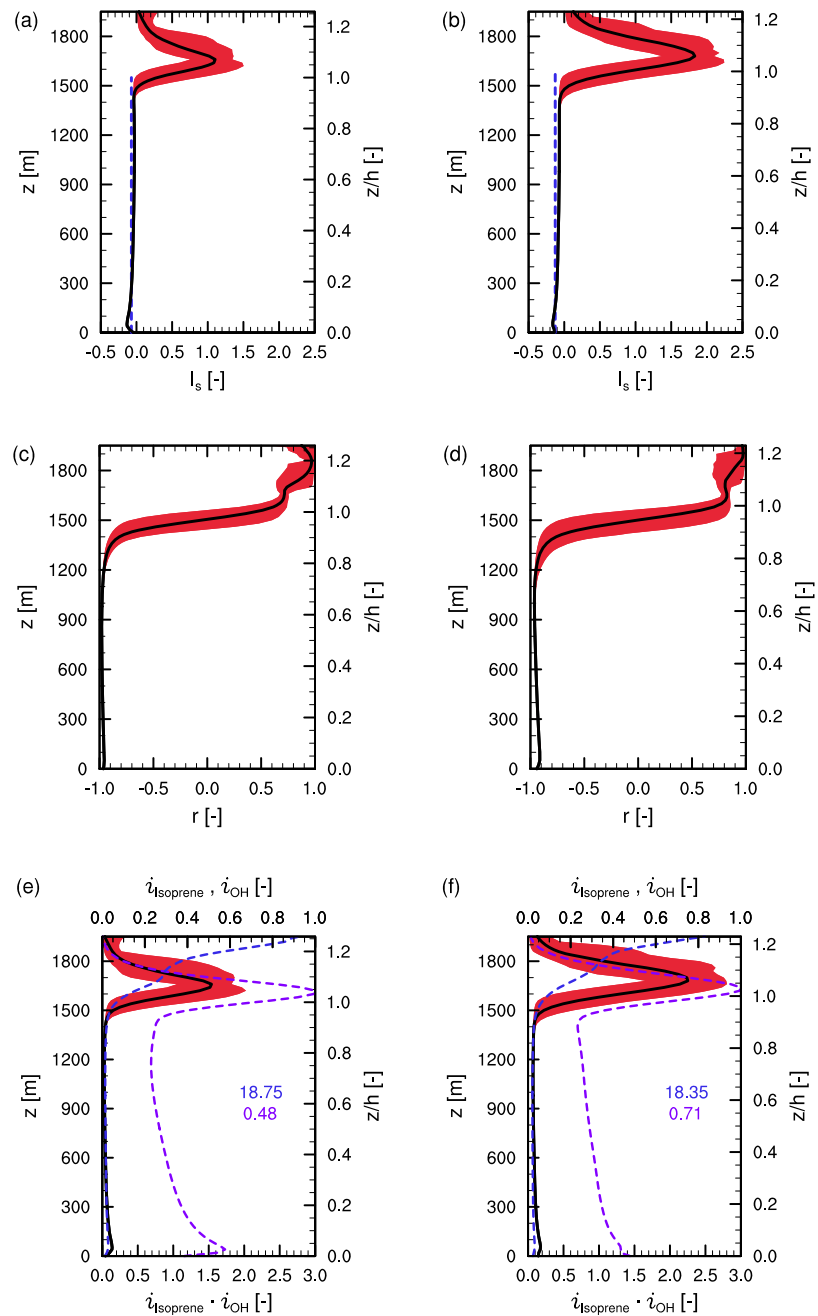

Fig. 6. Horizontal intensities of segregation and the contributing components, evaluating the isoprene-OH reaction. The fourth hour of the numerical experiments $\operatorname{HOM}(\mathbf{a}, \mathbf{c}, \mathbf{e})$ and HET $(\mathbf{b}, \mathbf{d}, \mathbf{f})$ is evaluated. At every height the instantaneous intensity of segregation over the horizontal plane is determined at intervals of $1 \mathrm{~min}$. Its averages are shown in (a) and (b) with the variability in time depicted using the red shading. The intensity of segregation over the entire boundary layer is shown by the blue dashed line. In (c) and (d) the horizontal spatial correlations between isoprene and $\mathrm{OH}$ are shown with their temporal variability. In (e) and (f) this is also done for the product of the concentration fluctuation intensities of $\mathrm{OH}$ and isoprene, i.e. the second term in Eq. (12). In blue and purple dashed lines the separate concentration fluctuation intensities are shown for isoprene and $\mathbf{O H}$, respectively. The numbers in (e) and (f) denote their unnormalized maximum values.

concentrations. In those regions the importance of Reaction (R9) to $\mathrm{OH}$ is relatively low compared to other chemical reactions.

Above the boundary layer, isoprene and $\mathrm{OH}$ are strongly positively correlated, indicating that $\mathrm{OH}$ producing compounds and isoprene are transported together into the free troposphere (Sect. 2.3). In the free troposphere, the concen- trations of these compounds are initially very low, as shown in Fig. 4. Therefore, at locations where thermals have transported compounds to the free troposphere, the concentrations of both $\mathrm{OH}$ and isoprene are higher than the surroundings. This results in a positive correlation. The figures show that the only height at which the magnitude of the intensity of segregation is influenced by the correlation factor, is near the entrainment zone. There the correlation factor changes sign over approximately $100 \mathrm{~m}$, decreasing and increasing again in magnitude in the process. The correlation factor does determine the sign of the intensity of segregation, since the concentration fluctuation intensities are positive by definition. In the case of isoprene and the hydroxyl radical, the intensity of segregation is therefore negative in the whole boundary layer and positive above.

The products of the concentration fluctuation intensities for isoprene and $\mathrm{OH}, i_{\text {Isoprene }} \cdot i_{\mathrm{OH}}$, drawn with the black lines in Fig. 6e and f, are shaped similar for both a homogeneous and heterogeneous surface forcing. Near the surface a small peak is present, which is caused by a relatively high concentration fluctuation intensity of $\mathrm{OH}$. This is caused by the high isoprene concentrations near the surface, resulting in rapid depletion of the hydroxyl radical. Above the boundary layer, the relative variabilities of both compounds peak. This is due to local transport through the inversion layer. While the average concentrations decrease with height, the standard deviations slightly increase in that region. Above this layer, also the standard deviations drop with height. Since the area of transport by thermals grows smaller with increasing height, the concentration fluctuation intensity for isoprene still increases with height. Due to fast depletion, $\mathrm{OH}$ is characterized by a more uniform concentration in the free troposphere. For the heterogeneous surface forcing the product of the concentration fluctuation intensities for isoprene and $\mathrm{OH}$ is enhanced, mostly due to $\mathrm{OH}$. In turn, this leads to an increase in magnitude of the horizontal segregation intensity.

\subsection{Influence of background wind}

In the previous simulations background wind was not present (i.e. local free convection). In this section its influence will be discussed. For the numerical experiments presented here, the roughness length, $z_{0}$, is kept constant to $0.1 \mathrm{~m}$. The validity of this parameter for our numerical experiments is checked by applying a roughness length of $1 \mathrm{~m}$ for the forest areas and $0.03 \mathrm{~m}$ for the savannah areas. The resulting differences in the main properties are very small for the conditions studied (not shown). Another effect not taken into account in this study is the possibility of differences in the background wind between the boundary layer and the free troposphere. The wind shear generates additional turbulence near the inversion layer, thereby increasing entrainment (e.g. Pino et al., 2003). In turn, this enhanced entrainment would influence both dynamics and chemistry. However, in all simulations presented here, the wind profiles are set constant with height. 

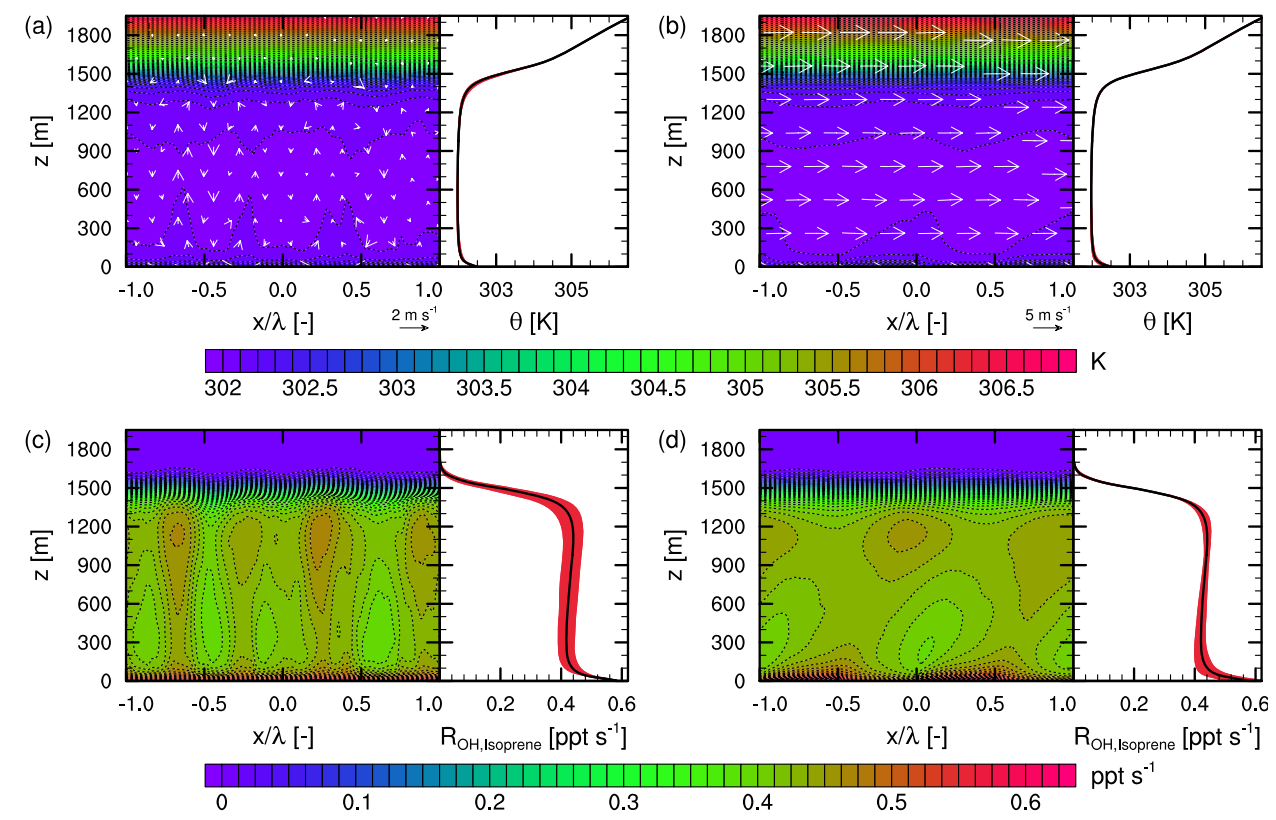

Fig. 7. Potential temperature and chemical reaction rate for Reaction (R9) for the numerical experiments WU2 (a, c) and WX2 (b, d). WU2 evaluates a homogeneous surface forcing with a background wind of $5 \mathrm{~m} \mathrm{~s}^{-1}$ in the positive y-direction. In the numerical experiment WX2 a heterogeneous surface forcing is applied with a background wind of $5 \mathrm{~m} \mathrm{~s}^{-1}$ in the positive $\mathrm{x}$-direction. The potential temperature, $\theta$, is shown on top $(\mathbf{a}, \mathbf{b})$ and the chemical reaction rate, $R_{\mathrm{OH}}$,Isoprene, below $(\mathbf{c}, \mathbf{d})$. Each figure consists of two panels. The first panel shows these variables averaged over the fourth hour of simulated time and the y-direction, while the second panel shows an additional average in the $\mathrm{x}$-direction. The red area in the second panel shows the variability in the $\mathrm{x}$-direction of the temporal and y averaged values. Wind direction in the xz-plane and its magnitude are indicated by vectors $(\mathbf{a}, \mathbf{b})$. The $\mathrm{x}$-coordinate is scaled by the length scale of heterogeneity, $\lambda$, which is twice the patch size.

In Fig. 7 the potential temperature and chemical reaction rate of Reaction (R9) are shown for the numerical experiments WU2 and WX2. Both experiments have a background wind of $5 \mathrm{~m} \mathrm{~s}^{-1}$ (constant with height). In the case of WU2 a homogeneous surface forcing is applied with a background wind pointing in the y-direction. WX2 is characterized by a heterogeneous surface forcing and a background wind pointing in the $\mathrm{x}$-direction. This corresponds to wind blowing perpendicular to the borders between the savannah and forest patches. In Fig. 7a it is visible that with a uniform surface forcing, mesoscale circulations are induced in the plane orthogonal to the direction of the background wind. These structures are called horizontal roll vortices (e.g. Stull, 1988; Young et al., 2002). At locations where the air is rising, the potential temperature in the lower part of the boundary layer is higher due to transport of air from the relatively warm surface layer. Chemistry is influenced by these circulations too, due to the horizontally heterogeneous vertical transport of chemical species. The rising branches of the circulations transport isoprene from the surface layer to the upper part of the boundary layer, which is where the hydroxyl radical mixing ratio is highest. Therefore, the chemical reaction rate of Reaction (R9) is higher in the upward moving air than in the downward moving air and has an increased horizon- tal variability compared to the numerical experiment without background wind (HOM), as shown in Fig. 7c. Due to the uneven distribution of isoprene and its depleting effect on the hydroxyl radical, the segregation between isoprene and $\mathrm{OH}$ is enhanced.

The influence of background wind on the turbulent coherent structures and the vertical wind velocity is shown in Fig. 8. The mesoscale circulations that are characteristic for a heterogeneous surface forcing are slightly enhanced by the horizontal roll vortices if both circulations exist in the same plane. The rising air in the core of the thermals is slower (with a velocity of approximately $1.8 \mathrm{~m} \mathrm{~s}^{-1}$ halfway up the boundary layer), but the structure of the thermals is wider. However, if the background wind blows across the boundaries between surface types, it inhibits the mesoscale circulations due to the extra mixing because of advection. Figure $7 \mathrm{~b}$ shows this suppresses the heterogeneous distribution of the potential temperature, compared to the local free convective case (Fig. 3b). Because of this the horizontal variability in the boundary layer height decreases. Consequently, the chemicals are more effectively mixed as well, resulting in more uniform chemical reaction rates in the boundary layer as illustrated by Fig. 7d. The dependence on wind direction and the significance of a background wind of $5 \mathrm{~m} \mathrm{~s}^{-1}$ is 

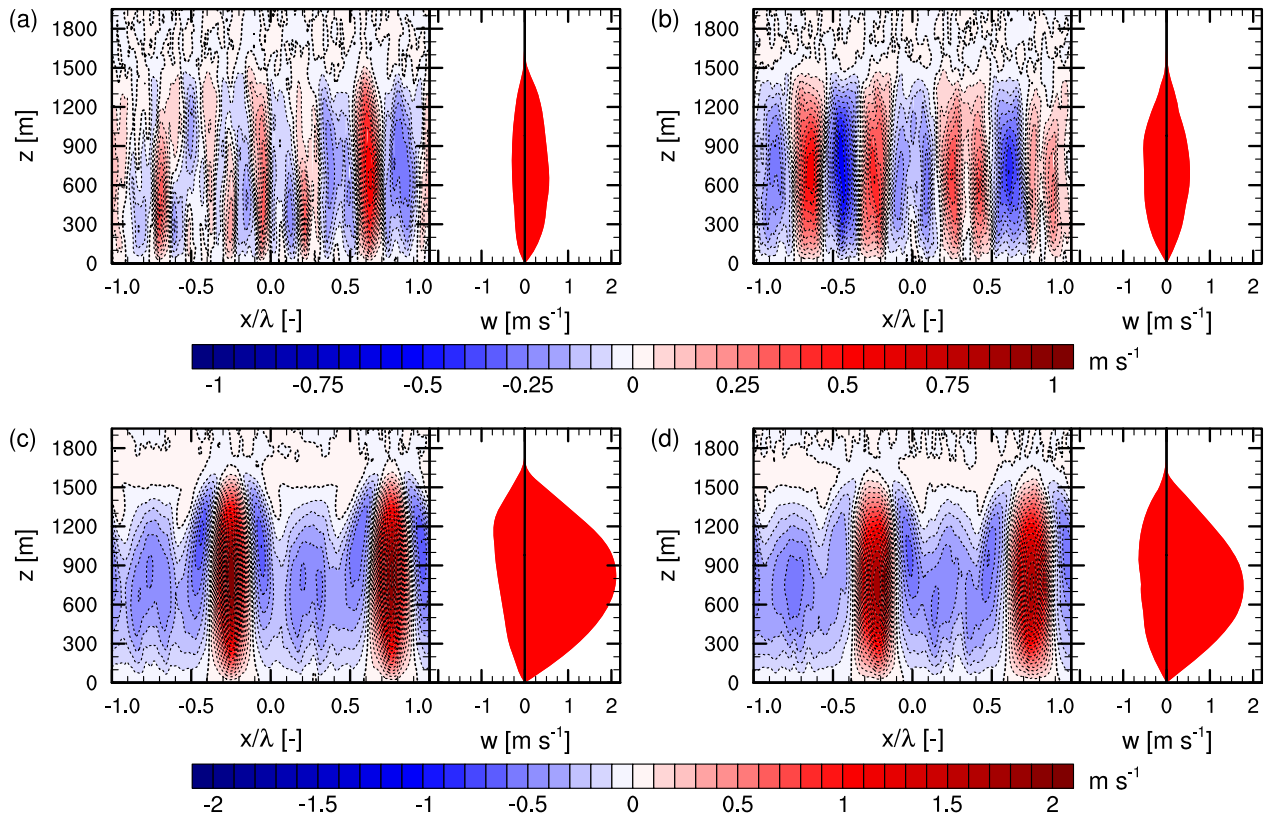

Fig. 8. Vertical wind velocity for the numerical experiments HOM (a), HET (c), WU2 (b) and WY2 (d). The upper figures are based on a homogeneous surface forcing while the lower figures are connected to a heterogeneous surface forcing. The background wind was set to $0 \mathrm{~m} \mathrm{~s}^{-1}$ for the numerical experiments shown in the left column and $5 \mathrm{~m} \mathrm{~s}^{-1}$ in the positive y-direction for the numerical experiments shown on the right. Each figure consists of two panels. The first panel shows these variables averaged over the fourth hour of simulated time and the $\mathrm{y}$-direction. The red area in the second panel shows the variability in the $\mathrm{x}$-direction of the temporal and $\mathrm{y}$ averaged values. The $\mathrm{x}$-coordinate is scaled by the length scale of heterogeneity, $\lambda$, which is twice the patch size.

in accordance with previous studies (Raasch and Harbusch, 2001; Kim et al., 2004).

Multiple numerical experiments have been performed with background wind for both kinds of surface forcing. The magnitudes were set to $2.5,5.0$ and $7.5 \mathrm{~m} \mathrm{~s}^{-1}$ and in the case of a heterogeneous surface forcing the wind direction was set either parallel or perpendicular to the borders. Figure 9 summarizes the effects on the boundary layer height and the intensity of segregation for the isoprene-OH reaction, Reaction (R9) (Table 2). The average boundary layer height slightly decreases for increasing wind velocities.

This seems to be caused by the lower vertical wind velocity maxima near the inversion layer with stronger background winds. For the cases with heterogeneous surface forcing and wind across the boundaries of the patches, the mixing effect of the background wind dominates the effect of surface heterogeneity. Therefore, the characteristics tend towards values representative for a homogeneous surface and the decrease in boundary layer height is strongest for these numerical experiments.

In general, chemicals are segregated more if a background wind is present, resulting in the heterogeneous chemical reaction rate of Fig. 7c. Figure 9b shows that this effect increases with the wind velocity. However, in the case of a heterogeneous surface forcing and advection across the patch borders, the magnitude of the intensity of segregation de- creases. Again, this is due to the background wind smoothing the effect of surface heterogeneity: by enhancing the mixing of chemical species, the reactants are segregated less.

\subsection{Influence of the length scale of heterogeneity}

Previous studies have shown that the impact of a heterogeneous surface forcing on dynamics is highly dependent on the length scale of heterogeneity (e.g. Avissar and Schmidt, 1998; Raasch and Harbusch, 2001; Patton et al., 2005). Also the effects on atmospheric chemistry depend on this length scale. Figure 10 shows the sensitivities of the boundary layer height and the intensity of segregation of the isoprene$\mathrm{OH}$ Reaction (R9). Note that in this analysis, length scales are scaled by the boundary layer height. When analysing the TKE, scaled by the convective velocity, as a function of the normalized length scale in a similar way as Patton et al. (2005), we qualitatively find the same sensitivity (not shown), but the maxima of TKE occur at $\lambda \approx 16 h_{\mathrm{BL}}$ instead of $\lambda \approx 8 h_{\mathrm{BL}}$. Therefore a more appropriate scaling might exist. 


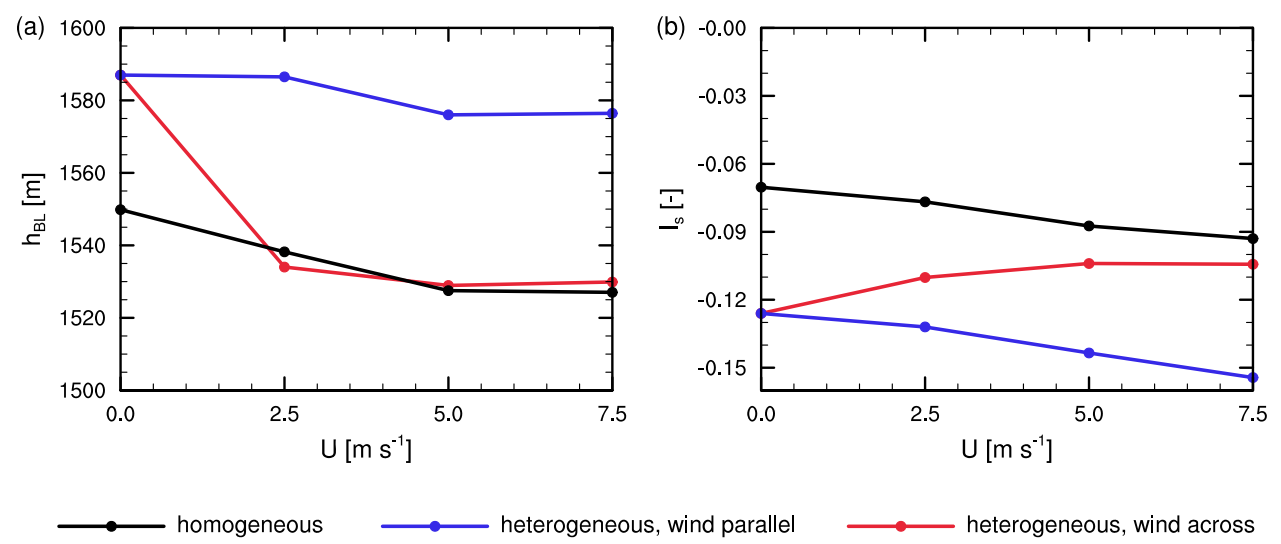

Fig. 9. Dependency of the boundary layer height (a) and the intensity of segregation in the boundary layer for Reaction (R9) (b) on horizontal wind. The plotted variables are averages over the fourth hour of simulated time. The boundary layer heights are additionally averaged in the $\mathrm{x}$-direction. The black lines represent the numerical experiments with a homogeneous surface forcing, while the other two lines are based on cases with a heterogeneous surface forcing. For these cases, the wind can have two directions. The blue lines correspond to wind blowing parallel to the borders between the grass and savannah patches, i.e. in the y-direction, and the red lines correspond to wind blowing across these borders, i.e. in the $\mathrm{x}$-direction.
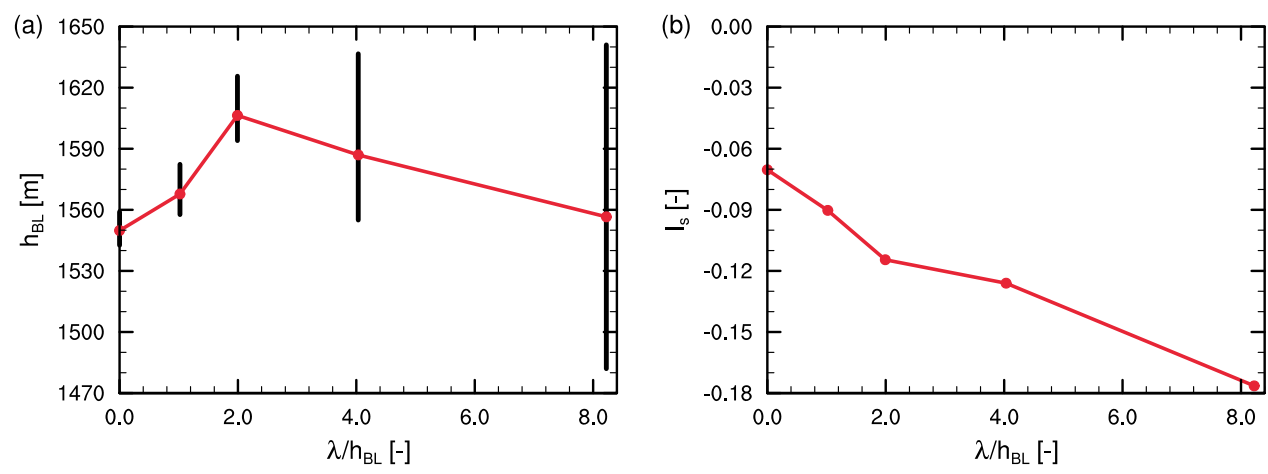

Fig. 10. Dependency of the boundary layer height (a) and the intensity of segregation in the boundary layer for the isoprene-OH Reaction (R9) (b) on the length scale of heterogeneity (i.e. twice the patch size). The homogeneous surface forcing corresponds to a heterogeneous surface forcing with a length scale of $0 \mathrm{~m}$. The plotted variables are averages over the fourth hour of simulated time. The boundary layer heights are additionally averaged in the x-direction. The length scales on the bottom axes are normalized by the corresponding averaged boundary layer heights, $h_{\mathrm{BL}}$. In (a) the black vertical lines represent the variability in the hourly averaged boundary layer height in the $\mathrm{x}$-direction.

In the case of the shorter length scales $\left(\lambda<2 h_{\mathrm{BL}}\right)$, stronger mesoscale motions are induced for an increase in length scale. Consequently, the upward moving thermals are more localized over the savannah and therefore stronger. Due to the more vigorous thermals over the savannah patches, entrainment becomes stronger, which leads to enhanced boundary layer heights over the savannah, explaining the increase in the maxima. At larger length scales, the cores of the thermals increase in size if the length scale increases. Therefore, entrainment does not intensify and the boundary layer height maxima over the savannah remain the same. For very large length scales $\left(\lambda>16 h_{\mathrm{BL}}\right)$ the boundary layer over the centre of the savannah (forest) patch is not affected by the surface forcing of the forest (savannah), which is visible in Fig. 11. This shows a separation of the combined boundary layer into separate boundary layers over the forest and savannah areas. The only interaction occurs near the interface (for our cases approximately $10 \mathrm{~km}$ wide) where a circulation still exists. If the boundary layers are fully separated, increasing the length scale of heterogeneity will not have any effect.

In the case of induced mesoscale circulations, hot air at the top of the boundary layer is transported from the savannah to the forest patches. Since no distinct temperature inversion is present over the forests (see Fig. 2a), the resulting heating enables more rapid boundary layer growth by generating a more gradual transition in temperature to the free tropospheric lapse rate. Therefore, for the smaller length scales, also over the forest areas the boundary layer heights increase with increasing length scale. However, in the case of larger length scales $\left(\lambda>2 h_{\mathrm{BL}}\right)$, direct entrainment of air from the 

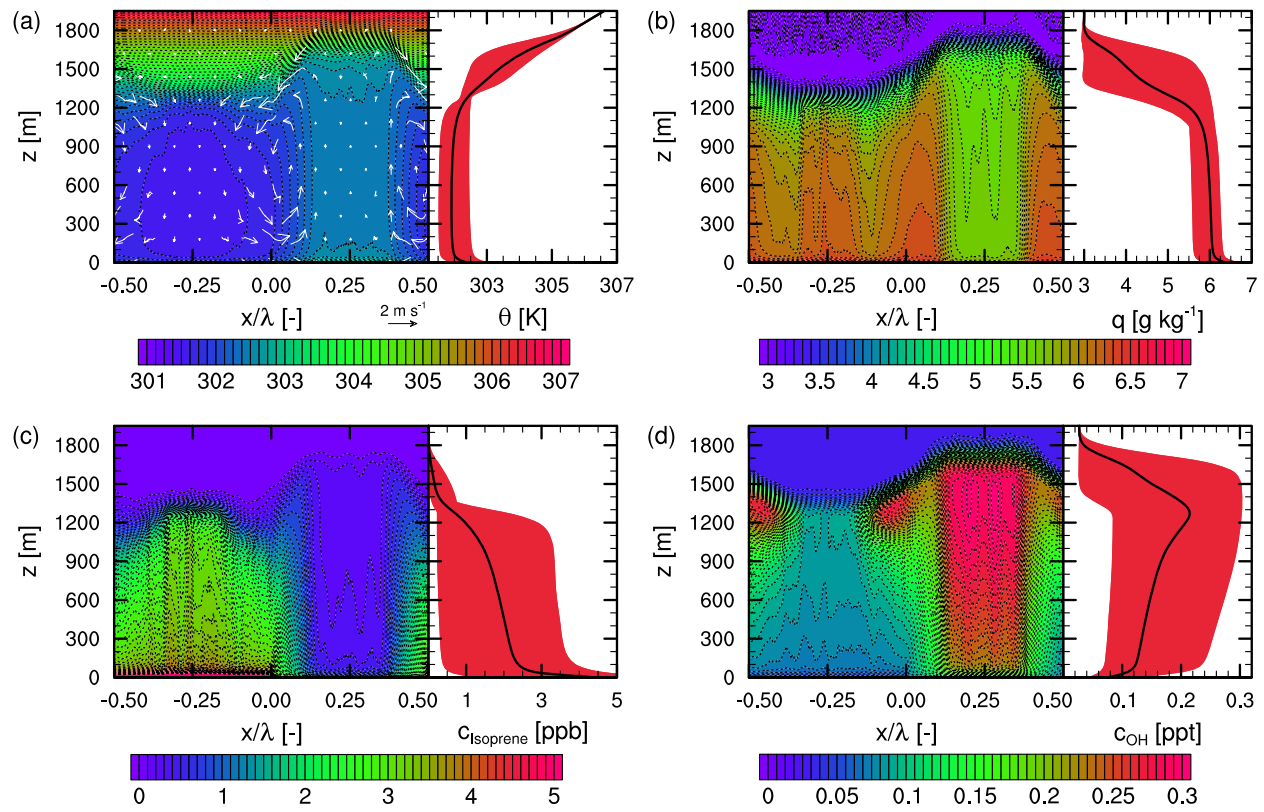

Fig. 11. The potential temperature (a), specific humidity (b), isoprene concentration (c) and $\mathrm{OH}$ concentration (d) for the fourth hour of the numerical experiment LSB2. The length scale of heterogeneity, $\lambda$, is $51.2 \mathrm{~km}$, which is equal to 33.5 times the averaged boundary layer height during this period. Each figure consists of two panels. The first panel shows the variables averaged over the fourth hour of simulated time and the $y$-direction, while the second panel shows an additional average in the $\mathrm{x}$-direction. The red area in the second panel shows the variability in the $\mathrm{x}$-direction of the temporal and y averaged values. Wind direction and magnitude are indicated by vectors (a).

free troposphere does not occur over the forests due to the mesoscale circulations, in accord with the findings of van Heerwaarden and Vilà-Guerau de Arellano (2008). In addition, in those cases the relative amount of transported heat from the savannah areas compared to the size of the forest areas decreases with an increasing length scale, leading to a decrease in the boundary layer heights over the forests. The domain-averaged boundary layer height decreases due to this more uneven distribution of entrained air as well.

The distribution of reactive species is also affected by the length scale. In this analysis the focus is on isoprene and $\mathrm{OH}$. For the shorter length scales $\left(\lambda<2 h_{\mathrm{BL}}\right)$, the non-uniformly distributed isoprene, due to heterogeneous surface emissions, is mixed within the surface layer (Mahrt, 2000). Therefore the strongest effect on the chemistry is an enhancement of the horizontal segregation in the surface layer. For increasing length scales, the mesoscale circulations become stronger, transporting isoprene from the forests to the savannah. The combination of the induced transport by the mesoscale circulations and the depletion by $\mathrm{OH}$ leads to increasing concentrations of isoprene over the savannah areas and lower concentrations in the upper part of the boundary layer over the forest areas. Since $\mathrm{OH}$ and isoprene react efficiently, the distribution of $\mathrm{OH}$ is affected in an opposite direction, leading to additional segregation.

For even larger length scales ( $\lambda \geq 16 h_{\mathrm{BL}}$, not shown), separation of the boundary layer between forest and savan- nah sets in (Avissar and Schmidt, 1998). Almost no isoprene emitted from the forest will be transported to the savannah areas. The concentration of $\mathrm{OH}$ over the savannah will therefore be much higher than over the forest, resulting in a spatial segregation of the reactive species between the boundary layer over the forest and over the savannah. In atmospheric chemistry models the intensity of segregation is sometimes used to account for the changed chemical reaction rates (Eq. 10) (e.g. Butler et al., 2008). However, for these length scales, both areas can have completely different dynamical and chemical characteristics, and the intensity of segregation concept can no longer be applied over the entire domain. Therefore, both areas should be treated separately instead of considering a single mixed boundary layer if $\lambda \geq 16 h_{\mathrm{BL}}$. This corresponds to a length scale of approximately $25 \mathrm{~km}$, which is of the same magnitude as the grid size of meso-scale chemistry-transport models and smaller compared to global climate models. For regions with surface heterogeneity length scales of that magnitude, chemistrytransport models should use a finer grid or nested models to accurately resolve the boundary layer chemistry.

All numerical experiments performed in this study consider 1D-heterogeneity of the land surface. Courault et al. (2007) found that 2-D-heterogeneity leads to weaker induced circulations. Relating these findings with the quantification in Table 4 suggests that in those cases the absolute value of the intensity of segregation will be lower. Further research 

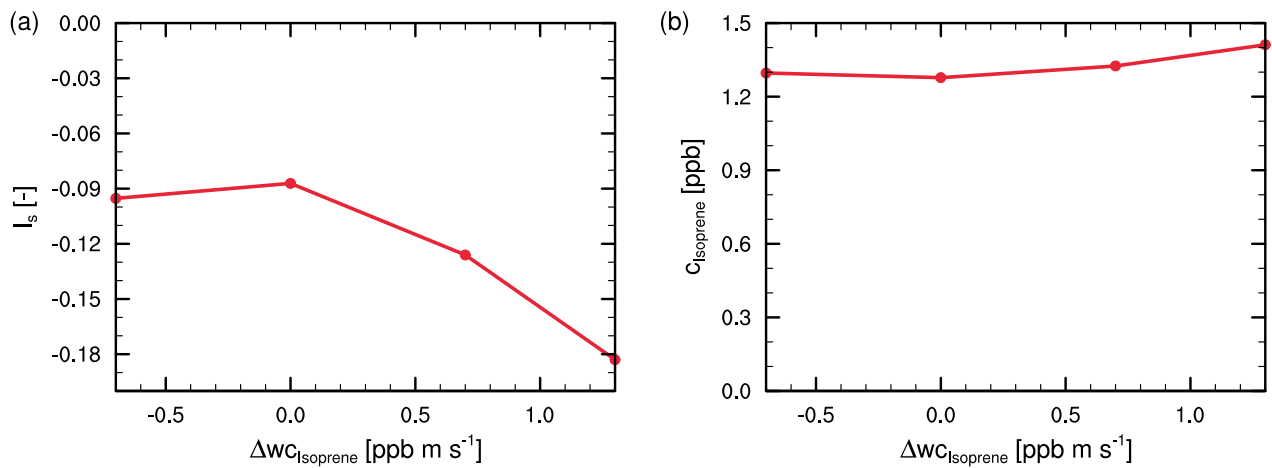

Fig. 12. Dependency of the intensity of segregation in the boundary layer for Reaction (R9) (a) and the boundary layer averaged concentration of isoprene (b) on the difference in isoprene emissions between forest and savannah areas. The average isoprene emission is $0.65 \mathrm{ppb}^{\mathrm{m} \mathrm{s}}{ }^{-1}$. The plotted variables are averages over the fourth hour of simulated time and the whole boundary layer. The values on the bottom axis are equal to $\overline{w^{\prime} c^{\prime}}$ Isoprene,forest $-\overline{w^{\prime} c^{\prime}}$ Isoprene, savannah.

on this subject is required, but this lies beyond the scope of this study.

\subsection{Influence of the difference in isoprene emissions}

In our model, the heterogeneity of isoprene emissions does not affect boundary layer dynamics, but it does influence atmospheric chemistry. The numerical experiments that are discussed in this section are characterized by the heterogeneous surface heat fluxes of case HET. Figure 12a shows that with heterogeneous surface heat fluxes the intensity of segregation is enhanced compared to the numerical experiment $\operatorname{HOM}\left(I_{\mathrm{S}}=-0.07\right)$, even if the isoprene emission from the surface is uniformly distributed. This segregation is caused by the transport (near the surface) of isoprene from the forest to the savannah by the induced mesoscale circulations and the following upward transport. During transport, isoprene is depleted by $\mathrm{OH}$. The isoprene concentration is lower by the time the air is advected to the forest area at the top of the boundary layer. Consequently, in the bulk of the boundary layer high isoprene concentrations are found over the savannah and low isoprene concentrations over the forest. Since the hydroxyl radical concentrations respond to the isoprene concentrations, the reverse is true for $\mathrm{OH}$. This leads to horizontal segregation. In the case where the isoprene emission from the savannah is higher than from the forest $\left(\Delta w c_{\text {Isoprene }}=-0.7 \mathrm{ppb} \mathrm{m} \mathrm{s}^{-1}\right.$ in Fig. 12), this effect is slightly enhanced.

Not all isoprene is transported to the savannah by the induced mesoscale circulations. The horizontal transport is strongest near the borders between savannah and forest. If more isoprene is emitted over the forest, the average transport time of isoprene to the savannah area and then to the upper part of the boundary layer increases. Therefore, the concentration of isoprene over the forest increases relative to conditions with uniform emissions and, due to the ongoing chemical reaction with $\mathrm{OH}$, most isoprene will be located in the lower part of the boundary layer. Again, $\mathrm{OH}$ responds to the concentration of isoprene, resulting in higher concentrations in the top of the boundary layer and lower concentrations near the surface. This introduces additional segregation in the vertical direction.

The concentration of isoprene is plotted in Fig. 12b. The effective chemical reaction rate coefficient when using boundary layer averaged concentrations is equal to $k \cdot\left(1+I_{\mathrm{S}}\right)$ according to Eq. (10). In the case of stronger (more negative) segregation effects, the effective coefficient of Reaction (R9) is reduced, resulting in higher concentrations in the boundary layer. Isoprene is most strongly affected, with a concentration increase of up to $10.5 \%$ compared to the case with homogeneous isoprene emissions. After the build up of isoprene in the lower part of the boundary layer, a new chemical balance is reached. Therefore, the boundary layer averaged total chemical reaction rate is reduced only by $0.6 \%$. While the lifetime of isoprene is increased significantly by the increase in segregation, the lifetime of the short-lived hydroxyl radical remains short due to other chemical reactions. Therefore the concentration of isoprene will build up more than that of $\mathrm{OH}$ and consequently $\mathrm{OH}$ is also affected much less (only $0.5 \%$ ).

\subsection{Influence of the surface energy partitioning}

The effects of the surface energy partitioning on the boundary layer height and the intensity of segregation for Reaction (R9) (Table 2) are summarized in Fig. 13. The boundary layer height has a non-linear dependency on the difference in surface buoyancy flux between the forest and savannah. This is due to two competing effects of the induced mesoscale circulations. The circulations that are imposed on the boundary layer dynamics intensify with larger surface buoyancy flux differences. Therefore, more turbulence is generated over 

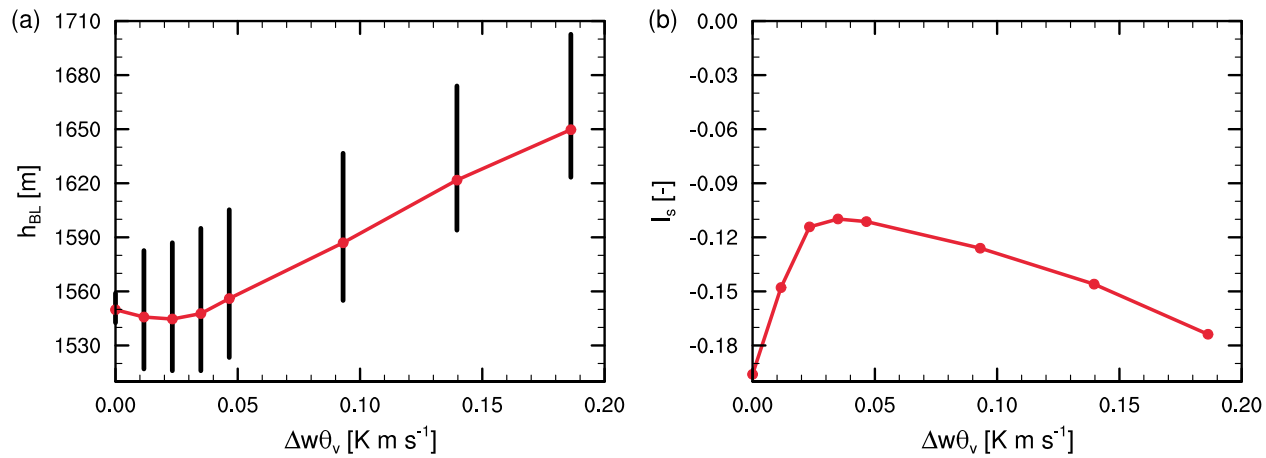

Fig. 13. Dependency of the boundary layer height (a) and the intensity of segregation in the boundary layer for Reaction (R9) (b) on the difference in surface buoyancy flux between forest and savannah areas. The plotted variables are averages over the fourth hour of simulated time. The boundary layer heights are additionally averaged in the x-direction. The values on the bottom axis are equal to $\overline{w^{\prime} \theta_{v}^{\prime}}$ savannah $-\overline{w^{\prime} \theta_{v}^{\prime}}$ Isoprene,forest. In (a) the black vertical lines represent the variability in the hourly averaged boundary layer height in the $\mathrm{x}$-direction.

the savannah areas and entrainment is increased, leading to higher boundary layers. By transport of air from the savannah to forest areas at the top of the boundary layer, the air over the forest is heated, resulting in the growth of the local boundary layer. For stronger circulations, the maximum boundary layer height is larger and entrained air has a higher potential temperature. Therefore the heating of the boundary layer over the forest is also stronger, which results in higher boundary layer height minima. The domain-averaged boundary layer height also increases due to this warmer entrained air.

The second effect is the suppression of turbulence over the forest by the downward moving branch of the induced circulations. Consequently, direct entrainment over the forest is reduced for increasing surface buoyancy flux differences and the local boundary layer height is lower. Therefore the boundary layer height minima decrease. This effect is relatively strong for weak mesoscale introductions which are related to small buoyancy flux differences $\left(\Delta \overline{w^{\prime} \theta_{v}^{\prime}}<\right.$ $\left.0.04 \mathrm{~K} \mathrm{~m} \mathrm{~s}^{-1}\right)$. For larger differences, all entrainment over the forest is suppressed and increasing the strength of the circulations only impacts the first of the two effects mentioned above. As a result the boundary layer height minima decrease with growing buoyancy flux differences as long as those differences are small $\left(\Delta \overline{w^{\prime} \theta_{v}^{\prime}}<0.023 \mathrm{~K} \mathrm{~m} \mathrm{~s}^{-1}\right)$ and increase in the case of larger differences.

Atmospheric chemistry depends strongly on the partitioning of the surface buoyancy flux. The effect on the intensity of segregation of Reaction (R9) is shown in Fig. 13b. Two regimes can be identified. For the regime with lower buoyancy flux differences, the segregation is governed by local emissions. In the case of larger buoyancy flux differences, the segregation is governed by mesoscale effects.

If the buoyancy flux is uniformly distributed, mixing in the vertical direction takes place due to thermals, but horizontal mixing is limited. The isoprene emitted by the forest stays in the boundary layer over the forest and the concentration of isoprene over the savannah is much lower. Consequently, the hydroxyl radical is mainly present in the boundary layer over the savannah. This leads to strong horizontal segregation that is approximately constant with height. For increasing differences in surface buoyancy fluxes, the mesoscale circulations become stronger. Near the surface, isoprene is transported from the forest to the savannah where vertical transport sets in. As a result, the horizontal mixing is stronger and the segregation is reduced. Depletion by $\mathrm{OH}$ limits the concentrations of isoprene in the upper part of the boundary layer, resulting in vertical segregation. The induced vertical segregation is weaker than the horizontal segregation, and the magnitude of the total intensity of segregation is reduced. For our numerical experiments this holds until $\Delta \overline{w^{\prime} \theta_{v}^{\prime}} \approx 0.035 \mathrm{~K} \mathrm{~m} \mathrm{~s}^{-1}$.

For even larger buoyancy flux differences, stronger induced circulations transport more isoprene from the forest to the savannah. The highest isoprene concentrations are now located over the savannah and in the lower part of the boundary layer over the forest. The $\mathrm{OH}$ concentration is therefore highest in the upper part of the boundary layer over the forest. For stronger circulations, the part of the boundary layer over the forest with high isoprene concentrations grows thinner, resulting in conditions with more negative horizontal segregation. In such cases the isoprene is more concentrated over the savannah and the hydroxyl radical over the forest. This corroborates the importance of a correct partitioning of the energy budget into surface moisture and heat fluxes when modelling atmospheric chemistry.

\subsection{Sensitivity to $\mathrm{NO}_{\mathrm{x}}$}

As mentioned in Sect. 2.2, sensitivity studies are performed on the role of $\mathrm{NO}_{\mathrm{x}}$. In particular we focus on the impact of biogenic $\mathrm{NO}_{\mathrm{x}}$ emissions and initial free tropospheric $\mathrm{NO}_{2}$. According to these numerical experiments, a one 

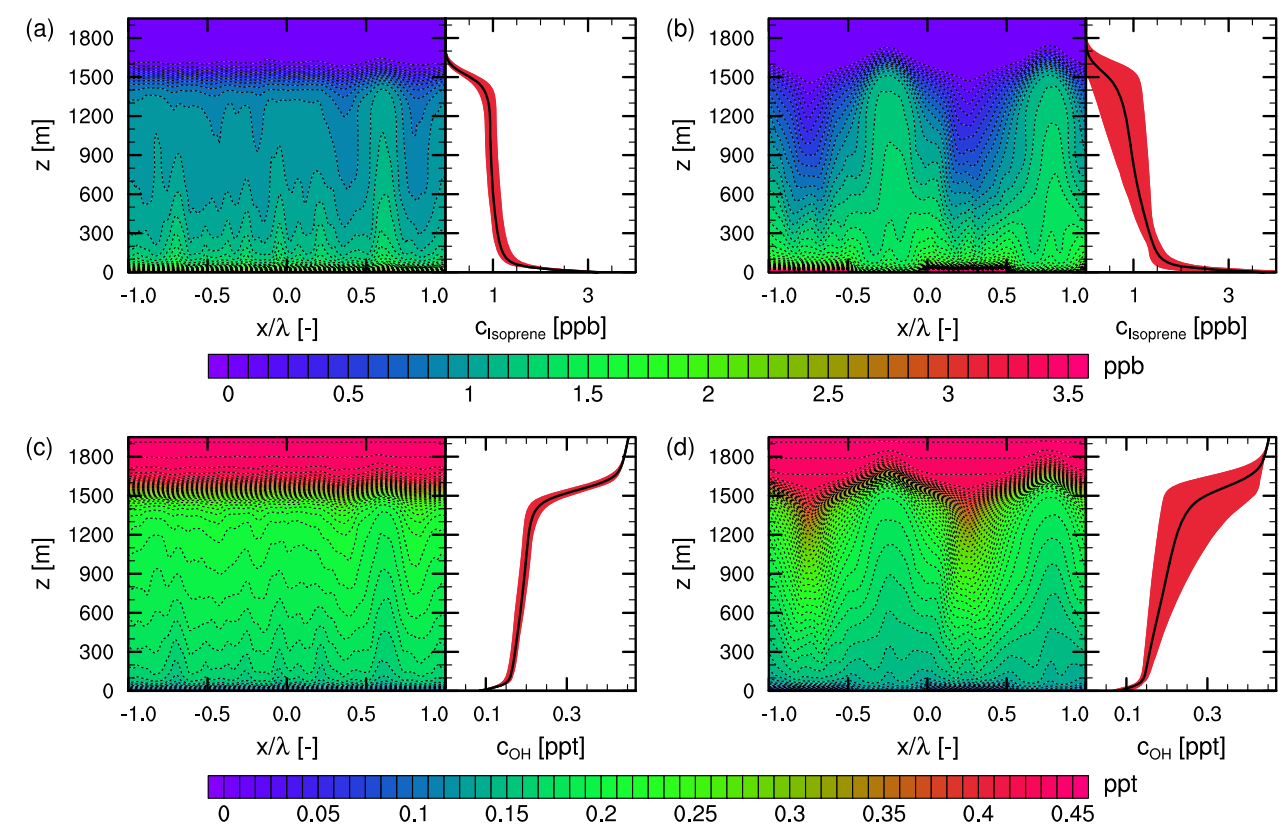

Fig. 14. Isoprene and $\mathrm{OH}$ concentrations for numerical experiments UNO (a, c) and HNO (b, d). They are identical to HOM and HET, respectively, except for the initial $\mathrm{NO}_{2}$ concentration above $1000 \mathrm{~m}$ (free troposphere). Each figure has two panels. The first shows the variables averaged over the fourth hour of simulation time and the y-direction, while the second panel shows the additional average in the $\mathrm{x}$-direction. The red area in the second panel shows the variability in the x-direction of the temporal and y averaged values. The concentration of isoprene, $c_{\text {Isoprene, }}$ is shown on top $(\mathbf{a}, \mathbf{b})$ and the concentration of the hydroxyl radical, $c_{\mathrm{OH}}$, at the bottom (c, $\left.\mathbf{d}\right)$. The $\mathrm{x}$-coordinate is scaled by the length scale of heterogeneity, $\lambda$, which is twice the patch size.

order of magnitude change in the prescribed NO emissions and changes in their distribution have limited impact on the isoprene-OH segregation under the chosen set of conditions. However, entrainment of $\mathrm{NO}_{\mathrm{x}}$ from the free troposphere, driven by the boundary layer growth in the morning hours, can significantly alter the boundary layer chemistry conditions. The presented numerical experiments (UNO and HNO) are based on cases HOM and HET, respectively, but have their initial free tropospheric $\mathrm{NO}_{2}$ concentration set to $0.5 \mathrm{ppb}$.

The temporal and y averaged profiles of the hydroxyl radical and isoprene concentrations are displayed in Fig. 14. $\mathrm{OH}$ is strongly affected by the free tropospheric $\mathrm{NO}_{\mathrm{x}}$. Note that in the free troposphere, the chemistry is characterized by higher hydroxyl radical concentrations due to the lower abundance of reduced species like isoprene. Therefore, air masses that are entrained from the free troposphere into the boundary layer are relatively rich in $\mathrm{NO}_{\mathrm{x}}$ and lead to higher $\mathrm{OH}$ concentrations. Since this process occurs at the top of the boundary layer, the spatial distribution of $\mathrm{OH}$ is changed and the gradients of the additional $\mathrm{x}$ averaged $\mathrm{OH}$ profiles indicate enhancements as well. The increase in $\mathrm{OH}$ subsequently depletes isoprene. Therefore, the isoprene concentration is lower compared to the cases without free tropospheric $\mathrm{NO}_{\mathrm{x}}$. However, the spatial pattern of isoprene remains similar to the cases without initial free tropospheric $\mathrm{NO}_{2}$.
The intensity of segregation for the isoprene-OH reaction is enhanced for the cases UNO and HNO. As mentioned, the free tropospheric air has a chemical composition that generates relatively high $\mathrm{OH}$ concentrations. This air enters the boundary layer at those edges of the layer that are positioned opposed to the locations of isoprene emissions. For example, for homogeneous surface forcings, isoprene is emitted at the surface and the entrained air is introduced at the top of the boundary layer. For heterogeneous surface forcings, i.e. when isoprene is mainly emitted by the forest (at $-1<\frac{x}{\lambda}<-0.5$ and $0<\frac{x}{\lambda}<0.5$ in Fig. 14), it is subsequently horizontally transported to the savannah region (at $-0.5<\frac{x}{\lambda}<0$ and $0.5<\frac{x}{\lambda}<1$ ) by the induced mesoscale circulations. There, the air is transported upwards. The entrained air, which is relatively enriched in $\mathrm{NO}_{\mathrm{x}}$ and consequently characterized by higher $\mathrm{OH}$ concentrations, is introduced at the top of the boundary layer over the savannah area and transported by the upper branch of a mesoscale circulation to the top of the boundary layer over the forest. There it is transported downwards by the subsiding branch of the induced mesoscale circulation. Consequently, the updrafts are rich in isoprene and poor in $\mathrm{OH}$, while in the downdrafts, which are poor in isoprene, the abundance of $\mathrm{OH}$ is enhanced due to the relatively high $\mathrm{NO}_{\mathrm{x}}$ concentration in the entrained air. This leads to enhanced spatial segregation compared to the cases without initial free tropospheric $\mathrm{NO}_{2}$. 

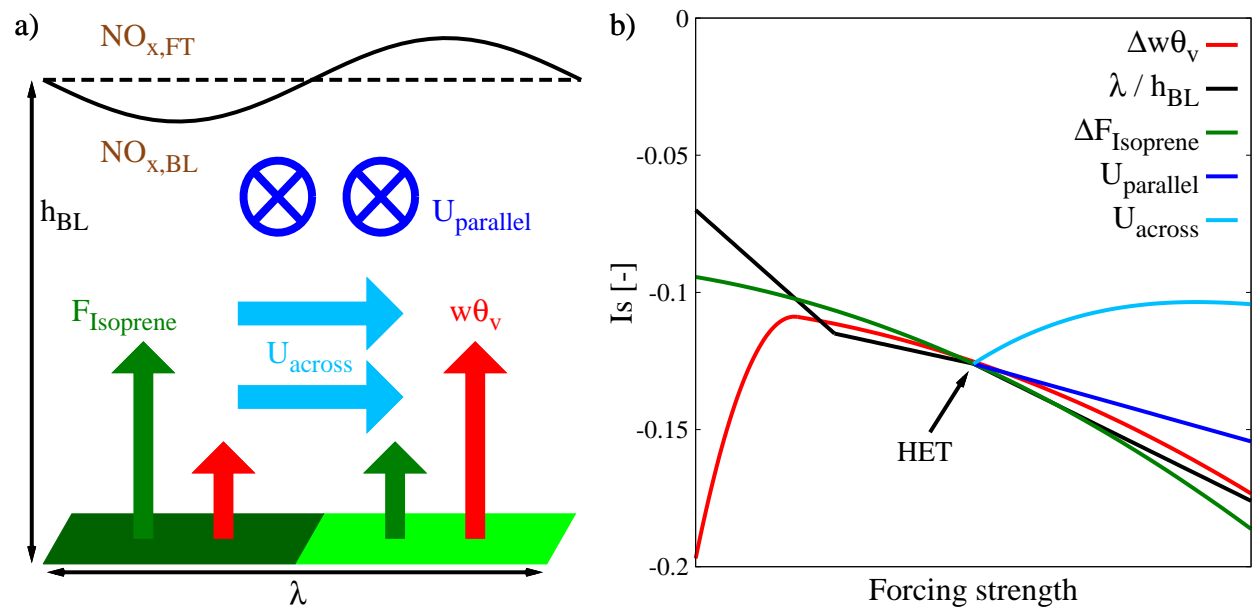

Fig. 15. Governing variables which affect the segregation of chemical species (a) and the resulting intensity of segregation for Reaction (R9) as a function of the magnitude of those variables (see descriptions of sensitivity analysis experiments in Table 3 and their results in Table 4 ) (b). The governing variables are the surface buoyancy flux difference, the length scale of heterogeneity, the isoprene emission difference, wind blowing parallel to the borders between forest and grass and wind blowing across those borders. The control numerical experiment with heterogeneous surface forcing, HET, is indicated with an arrow. Not shown in panel (b) is the impact of $\mathbf{N O}_{\mathrm{x}}$ mixing ratios and their distribution within the boundary layer and free troposphere on the intensity of segregation for Reaction (R9).

We find that averaged over the fourth hour of simulated time, the intensity of segregation is changed from -0.070 (HOM) to -0.124 (UNO) in the case of homogeneous surface forcings and from -0.126 (HET) to -0.209 (HNO) in the case of heterogeneous surface forcings.

These results show that $\mathrm{NO}_{\mathrm{x}}$ mixing ratios and their distribution within the boundary layer and free troposphere significantly influence the intensity of segregation for the isoprene$\mathrm{OH}$ reaction. It stresses the need to take the $\mathrm{VOC}$ and $\mathrm{NO}_{\mathrm{x}}$ conditions into account in future studies that aim at segregation parameterizations.

\section{Conclusions}

Numerical experiments with DALES, a model that simultaneously resolves turbulence and atmospheric chemistry at the most energetic and relevant scales, are used to systematically study boundary layer dynamics and mixing over a land surface characterized by heterogeneous conditions. Particular emphasis is put on the structure of the boundary layer and the intensity of segregation for the isoprene- $\mathrm{OH}$ reaction. The numerical experiments are based on conditions representative for the Amazon rain forest.

Figure 15 summarizes the main driving variables including a quantification of the intensity of segregation as a function of the magnitude of those variables. The results indicate that in the absence of free tropospheric $\mathrm{NO}_{\mathrm{x}}$ the intensity of segregation for the isoprene-OH reaction is normally in the range $-0.07>I_{\mathrm{S}}>-0.20$. The difference in surface buoyancy flux between the forest and savannah induces cir- culations that affect segregation. The impacts depend on the regime under study. For low buoyancy flux differences between savannah and forest, isoprene is mainly concentrated over the forest and an increase in the horizontal transport between the forest and savannah due to a larger difference leads to a lower magnitude of the intensity of segregation. For high buoyancy flux differences, most isoprene is located over the savannah and an increase of the surface buoyancy flux difference enhances this segregation. This non-linearity is visible in Fig. 15b. An increase in the length scale of heterogeneity always results in stronger segregation. However, for length scales of heterogeneity much larger than the boundary layer height $\left(\lambda>16 h_{\mathrm{BL}}\right)$ the centres of the boundary layers above each patch are hardly affected by the induced circulations that only occur in a narrow zone near the surface discontinuities. In these cases the intensity of segregation becomes more negative than -0.20 , but separation of the boundary layers can occur.

For larger differences in isoprene emissions between forest and savannah, more negative intensities of segregation are found. The intensity and direction of the background wind is of importance too. Wind parallel to the borders between forest and savannah enhances the induced circulations and the resulting intensity of segregation. Wind traversing these borders smoothens the effects of a heterogeneous surface forcing, which results in a weaker intensity of segregation.

In general, the results suggest that the intensity of segregation cannot be taken as a constant number based on averaged emissions and moisture and heat fluxes. It strongly depends on the background wind conditions and the partitioning of the emissions and surface fluxes. 
The intensity of segregation for the isoprene-OH reaction varies significantly between the different simulated conditions. However, with the exception of the cases in which the boundary layers become separated or $\mathrm{NO}_{\mathrm{x}}$ is entrained from the free troposphere, the boundary layer average concentration of $\mathrm{OH}$ is hardly modified. This is caused by an increase in the isoprene concentration, compensating for the segregation effect. The increase in isoprene concentration for these cases reaches values up to $12 \%$, which is actually within the $15 \%$ uncertainty in isoprene measurements (Karl et al., 2007). Consequently, the chemical reaction rates remain almost equal, which explains the satisfactory performance of mixed layer models that assume instantaneous mixing for atmospheric chemistry in the planetary boundary layer during diurnal convective conditions (e.g. Vilà-Guerau de Arellano et al., 2011).

The usual mismatch between $\mathrm{OH}$ observations and current state of the art atmospheric model by factors over 2 (Tan et al., 2001; Lelieveld et al., 2008) cannot be fully explained by the intensity of segregation. Since the difference in concentrations due to segregation is comparable to the measurement uncertainties and uncertainties in the reaction rate coefficients (5-15\%, Atkinson et al., 2006), representing the segregation is not the final solution to reconcile modelled and observed $\mathrm{OH}$ concentrations. Therefore, the implementation of parameterizations for the intensity of segregation for the sub-grid scale processes in large scale atmospheric chemistry-transport may not have first priority. However, parameterizations are needed when striving for the best possible model performance. This study shows dependences on the length scale of heterogeneity, the differences in surface buoyancy fluxes and isoprene emissions between forest and savannah and the intensity and direction of the background wind. These governing processes are interacting nonlinearly. Therefore, future research on representations of the intensity of segregation in chemistry-transport models needs to take these interactions between the different processes into account. An effort should be made to obtain observational data that can verify the results obtained from numerical experiments. Finally, our study shows that in order to help reconcile modelling with observations, it is recommendable to combine future measurements of atmospheric chemistry and boundary layer dynamics with a characterization of the heterogeneity of the land surface conditions and the direction and magnitude of the background wind.

Acknowledgements. H. O. gratefully acknowledges financial support by the Max Planck Society for this project. L. G. and M. K. acknowledge PEGASOS (grant agreement 265148) for financial support. The modelling part of this study was sponsored by the National Computing Facilities Foundation (NCF project SH-06011) for the use of supercomputer facilities. The authors thank Ian Faloona for his insightful comments that have helped improve the article.
The service charges for this open access publication have been covered by the Max Planck Society.

Edited by: S. Galmarini

\section{References}

Andreae, M. O., Artaxo, P., Brandao, C., Carswell, F. E., Ciccioli, P., da Costa, A. L., Culf, A. D., Esteves, J. L., Gash, J. H. C., Grace, J., Kabat, P., Lelieveld, J., Malhi, Y., Manzi, A. O., Meixner, F. X., Nobre, A. D., Nobre, C., Ruivo, M. L. P., Silva-Dias, M. A., Stefani, P., Valentini, R., von Jouanne, J., and Waterloo, M. J.: Biogeochemical cycling of carbon, water, energy, trace gases, and aerosols in Amazonia: The LBA-EUSTACH experiments, J. Geophys. Res., 107, 8066 , doi:10.1029/2001JD000524, 2002.

Atkinson, R., Baulch, D. L., Cox, R. A., Crowley, J. N., Hampson, R. F., Hynes, R. G., Jenkin, M. E., Rossi, M. J., and Troe, J.: Evaluated kinetic and photochemical data for atmosperic chemistry: Volume II - gas phase reactions of organic species, Atmos. Chem. Phys., 6, 3625-4055, doi:10.5194/acp-6-3625-2006, 2006.

Auger, L. and Legras, B.: Chemical segregation by heterogeneous emissions, Atmos. Environ., 41, 2302-2318, doi:10.1016/j.atmosenv.2006.11.032, 2007.

Avissar, R. and Liu, Y.: Three-dimensional numerical study of shallow convective clouds and precipitation induced by land surface forcing, J. Geophys. Res., 101, 7499-7518, doi:10.1029/95JD03031, 1996.

Avissar, R. and Schmidt, T.: An Evaluation of the Scale at which Ground-Surface Heat Flux Patchiness Affects the Convective Boundary Layer Using Large-Eddy Simulations, J. Atmos. Sci., 55, 2666-2689, 1998.

Butler, T. M., Taraborrelli, D., Brühl, C., Fischer, H., Harder, H., Martinez, M., Williams, J., Lawrence, M. G., and Lelieveld, J.: Improved simulation of isoprene oxidation chemistry with the ECHAM5/MESSy chemistry-climate model: lessons from the GABRIEL airborne field campaign, Atmos. Chem. Phys., 8, 4529-4546, doi:10.5194/acp-8-4529-2008, 2008.

Courault, D., Drobinski, P., Brunet, Y., Lacarrere, P., and Talbot, C.: Impact of surface heterogeneity on a buoyancy-driven convective boundary layer in light winds, Bound.-Lay. Meteorol., 124, 383 403, doi:10.1007/s10546-007-9172-y, 2007.

Cuijpers, J. W. M. and Duynkerke, P. G.: Large Eddy Simulation of Trade Wind Cumulus Clouds, J. Atmos. Sci., 50, 3894-3907, doi:10.1175/1520-0469(1993)050<3894:LESOTW>2.0.CO;2, 1993.

Dlugi, R., Berger, M., Zelger, M., Hofzumahaus, A., Siese, M., Holland, F., Wisthaler, A., Grabmer, W., Hansel, A., Koppmann, R., Kramm, G., Möllmann-Coers, and Knaps, A.: Turbulent exchange and segregation of $\mathrm{HO}_{x}$ radicals and volatile organic compounds above a deciduous forest, Atmos. Chem. Phys., 10, 6215-6235, doi:10.5194/acp-10-6215-2010, 2010.

Dosio, A.: Turbulent dispersion in the Atmospheric Convective Boundary Layer, Ph.D. thesis, Wageningen University, 2005.

Fisch, G., Tota, J., Machado, L. A. T., Silva Dias, M. A. F., Lyra, R. F. d. F., Nobre, C. A., Dolman, A. J., and Gash, J. H. C.: The convective boundary layer over pasture and forest in Ama- 
zonia, Theor. Appl. Climatol., 78, 47-59, doi:10.1007/s00704004-0043-x, 2004.

Ganzeveld, L., Eerdekens, G., Feig, G., Fischer, H., Harder, H., Königstedt, R., Kubistin, D., Martinez, M., Meixner, F. X., Scheeren, H. A., Sinha, V., Taraborrelli, D., Williams, J., VilàGuerau de Arellano, J., and Lelieveld, J.: Surface and boundary layer exchanges of volatile organic compounds, nitrogen oxides and ozone during the GABRIEL campaign, Atmos. Chem. Phys., 8, 6223-6243, doi:10.5194/acpd-8-11909-2008, 2008.

Ganzeveld, L., Bouwman, L., Stehfest, E., van Vuuren, D. P., Eickhout, B., and Lelieveld, J.: Impact of future land use and land cover changes on atmospheric chemistry climate interactions, J. Geophys. Res., 115, D23301, doi:10.1029/2010JD014041, 2010.

Garcia-Carreras, L., Parker, D. J., Taylor, C. M., Reeves, C. E., and Murphy, J. G.: Impact of mesoscale vegetation heterogeneities on the dynamical and thermodynamic properties of the planetary boundary layer, J. Geophys. Res., 115, D03102, doi:10.1029/2009JD012811, 2010.

Heus, T., van Heerwaarden, C. C., Jonker, H. J. J., Siebesma, A. P., Axelsen, S., van den Dries, K., Geoffroy, O., Moene, A., Pino, D., de Roode, S. R., and Vilà-Guerau de Arellano, J.: Formulation of the Dutch Atmospheric Large-Eddy Simulation (DALES) and overview of its applications, Geosci. Model Dev., 3, 415444, doi:10.5194/gmd-3-415-2010, 2010.

Karl, T., Guenther, A., Yokelson, R., Greenberg, J., Potosnak, M., Blake, D. R., and Artaxo, P.: The tropical forest and fire emissions experiment: Emission, chemistry, and transport of biogenic volatile organic compounds in the lower atmosphere over Amazonia, J. Geophys. Res., 112, D18302, doi:10.1029/2007JD008539, 2007.

Kesselmeier, J. and Staudt, M.: Biogenic Volatile Organic Compounds (VOC): An Overview on Emission, Physiology and Ecology, J. Atmos. Chem., 33, 23-88, doi:10.1023/A:1006127516791, 1999.

Kim, H.-J., Noh, Y., and Raasch, S.: Interaction between wind and temperature fields in the planetary boundary layer for a spatially heterogeneous surface heat flux, Bound.-Lay. Meteorol., 111, 225-246, doi:10.1023/B:BOUN.0000016471.75325.75, 2004.

Krol, M. C., Molemaker, M. J., and Vilà-Guerau de Arellano, J.: Effects of turbulence and heterogeneous emissions on photochemically active species in the convective boundary layer, J. Geophys. Res., 105, 6871-6884, doi:10.1029/1999JD900958, 2000.

Lelieveld, J., Butler, T. M., Crowley, J. N., Dillon, T. J., Fischer, H., Ganzeveld, L., Harder, H., Lawrence, M. G., Martinez, M., Taraborrelli, D., and Williams, J.: Atmospheric oxidation capacity sustained by a tropical forest, Nature, 452, 737-740, doi:10.1038/nature06870, 2008.

Mahrt, L.: Surface Heterogeneity and Vertical Structure of the Boundary Layer, Bound.-Lay. Meteorol., 96, 33-62, doi:10.1023/A:1002482332477, 2000.

Nieuwstadt, F. T. M. and Brost, R. A.: The Decay of Convective Turbulence, J. Atmos. Sci., 43, 532-545, doi:10.1175/15200469(1986)043<0532\%3ATDOCT > 2.0.CO;2, 1986.

Ouwersloot, H. G., Vilà-Guerau de Arellano, J., van Heerwaarden, C. C., Ganzeveld, L. N., Krol, M. C., and Lelieveld, J.: The significance of species segregation for Amazonian Chemistry, in: 19th Symposium on Boundary Layers and Turbulence/29th Conference on Agricultural and Forest Meteorology, AMS, extended abstract, 2010.
Patton, E. G., Sullivan, P. P., and Moeng, C.-H.: The Influence of Idealized Heterogeneity on Wet and Dry Planetary Boundary Layers Coupled to the Land Surface, J. Atmos. Sci., 62, 2078 2097, doi:10.1175/JAS3465.1, 2005.

Pino, D., Vilà-Guerau de Arellano, J., and Duynkerke, P. G.: The Contribution of Shear to the Evolution of a Convective Boundary Layer, J. Atmos. Sci., 60, 1913-1926, doi:10.1175/15200469(2003)060<1913\%3ATCOSTT > 2.0.CO\%3B2, 2003.

Pugh, T. A. M., MacKenzie, A. R., Hewitt, C. N., Langford, B., Edwards, P. M., Furneaux, K. L., Heard, D. E., Hopkins, J. R., Jones, C. E., Karunaharan, A., Lee, J., Mills, G., Misztal, P., Moller, S., Monks, P. S., and Whalley, L. K.: Simulating atmospheric composition over a South-East Asian tropical rainforest: performance of a chemistry box model, Atmos. Chem. Phys., 10, 279-298, doi:10.5194/acp-10-279-2010, 2010.

Pugh, T. A. M., MacKenzie, A. R., Langford, B., Nemitz, E., Misztal, P. K., and Hewitt, C. N.: The influence of small-scale variations in isoprene concentrations on atmospheric chemistry over a tropical rainforest, Atmos. Chem. Phys., 11, 4121-4134, doi:10.5194/acp-11-4121-2011, 2011.

Raasch, S. and Harbusch, G.: An analysis of secondary circulations and their effects caused by small-scale surface inhomogeneities using large-eddy simulation, Bound.-Lay. Meteorol., 101, 31-59, doi:10.1023/A:1019297504109, 2001.

Schumann, U.: Large-Eddy Simulation of Turbulent Diffusion with Chemical Reactions in the Convective Boundary Layer, Atmos. Environ., 23, 1713-1727, doi:10.1016/0004-6981(89)90056-5, 1989.

Soares-Filho, B. S., Nepstad, D. C., Curran, L. M., Cerqueira, G. C., Garcia, R. A., Ramos, C. A., Voll, E., McDonald, A., Lefebvre, P., and Schlesinger, P.: Modelling conservation in the Amazon basin, Nature, 440, 520-523, doi:10.1038/nature04389, 2006.

Stull, R. B.: An Introduction to Boundary Layer Meteorology, Kluwer Academic Publishers, 1988.

Sullivan, P. P., Moeng, C.-H., Stevens, B., Lenschow, D. H., and Mayor, S. D.: Structure of the Entrainment Zone Capping the Convective Atmospheric Boundary Layer, J. Atmos. Sci., 55, 3042-3064, 1998.

Sykes, R. I., Henn, D. S., Parker, S. F., and Lewellen, W. S.: Largeeddy simulation of a turbulent reacting plume, Atmos. Environ. 26A, 2565-2574, doi:10.1016/0960-1686(92)90109-X, 1992.

Tan, D., Faloona, I., Simpas, J. B., Brune, W., Shepson, P. B., Couch, T. L., Sumner, A. L., Carroll, M. A., Thornberry, T., Apel, E., Riemer, D., and Stockwell, W.: $\mathrm{HO}_{x}$ budgets in a deciduous forest: Results from the PROPHET summer 1998 campaign, J. Geophys. Res., 106, 24407-24427, doi:10.1029/2001JD900016, 2001.

van Heerwaarden, C. C. and Vilà-Guerau de Arellano, J.: Relative Humidity as an Indicator for Cloud Formation over Heterogeneous Land Surfaces, J. Atmos. Sci., 65, 3263-3277, doi:10.1175/2008JAS2591.1, 2008.

Vilà-Guerau de Arellano, J., Duynkerke, P. G., Jonker, P. J., and Builtjes, P. J. H.: An Observational Study on the Effects of Time and Space Averaging in Photochemical Models, Atmos. Environ., 27A, 353-362, doi:10.1016/0960-1686(93)90109-C, 1993.

Vilà-Guerau de Arellano, J., Kim, S.-W., Barth, M. C., and Patton, E. G.: Transport and chemical transformations influenced by shallow cumulus over land, Atmos. Chem. Phys., 5, 3219-3231, doi:10.5194/acp-5-3219-2005, 2005. 
Vilà-Guerau de Arellano, J., van den Dries, K., and Pino, D.: On inferring Isoprene Emission Surface Flux from Atmospheric Boundary Layer Concentration Measurements, Atmos. Chem. Phys., 9, 3629-3640, doi:10.5194/acp-9-3629-2009, 2009.

Vilà-Guerau de Arellano, J., Patton, E. G., Karl, T., van den Dries, K., Barth, M. C., and Orlando, J. J.: The role of boundary layer dynamics on the diurnal evolution of isoprene and the hydroxyl radical over tropical forests, J. Geophys. Res., 116, D07304, doi:10.1029/2010JD014857, in press, 2011.

Vinuesa, J.-F. and Vilà-Guerau de Arellano, J.: Fluxes and (co)variances of reacting scalars in the convective boundary layer, Tellus B, 55, 935-949, doi:10.1046/j.1435-6935.2003.00073.x, 2003.
Young, G. S., Kristovich, A. R., Hjelmfelt, M. R., and Foster, R. C.: Rolls, Streets, Waves, and More: A Review of Quasi-TwoDimensional Structures in the Atmospheric Boundary Layer, B. Am. Meteorol. Soc., 83, 997-1001, 2002.

Zimmerman, P. R., Greenberg, J. P., and Westberg, C. E.: Measurement of atmospheric hydrocarbons and biogenic emission fluxes in the Amazon boundary layer, J. Geophys. Res., 93, 1407-1416, doi:10.1029/JD093iD02p01407, 1988. 